\title{
Beobachtungen aus der Umgegend von Posen.
}

\section{Von J. Hammling und $\mathrm{K}$. Schulz.}

$\mathrm{Um}$ auf Grund eigener Beobachtangen einen möglichst vollständigen Überblick über die Vogelwelt zunächst eines Teiles unsrer ornithologisch bisher etwas vernachlässigten Heimatprovinz zu gewinnen, haben wir uns auf ein verhältnismälsig kleines Gebiet beschränkt. Dieses Gebiet wird von Norden nach Süden durch das Warthetal durchschnitten. Mittelpunkt des Gebietes, von beiden Endpunkten desselben so ziemlich gleich weit entfernt, ist Posen. Unsre Provinzialhauptstadt liegt am, teilweise im Tal der mittleren Warthe, dem in der Hauptsache in nordsüdlicher Richtung verlaufenden Verbindungstal zwischen dem ThornEberswalder und Warschau-Berliner Urstromtale, die unsere Provinz in westöstlicher Richtung schneiden. Schon hieraus ist ersichtlich, dals unser Beobachtungsgebiet nicht im Bereiche einer Hauptzugstrafse gelegen ist. Diese werden vielmehr in der Richtung der Urstromtäler verlaufen, wie wir dies für das nördliche der beiden genannten Haupttäler vielfach bestätigt gefunden haben. Aufser dem Warthetal kamen für unsre Zwecke noch die nicht unbedeutenden Seitentäler der von Osten und Westen her unmittelbar bei Posen in die Warthe einmündenden Flüfschen Cybinoa und Bogdanka in Betracht.

Das ziemlich tief in die wellige Posener Diluviallandschaft eingeschnittene Warthetal, d. $h$. das jetzige Überschwemmungsgebiet der Warthe, ist durchschnittlich $1 / 2$ bis $11 / 2 \mathrm{~km}$ breit. Etwa $5 \mathrm{~km}$ oberhalb Posens liegt am linken̉ Flufsufer der Eichwald (Schutzbezirk Luisenhain, zur Königl. Oberförsterei Lud wigsberg gehörig), ein beliebter Ausflugspankt der Posener. Der Luisenhain, 83,366 ha grofs, ${ }^{1}$ ) liegt im Überschwemmungsgebiete der Warthe. Er besteht zu einem grolsen Teile aus Kiefern, die besonders am Nord- und Südrande einen bis zu 75 Jahre alten Bestand aufweisen. 2) In der Mitte, südlich des den Wald durchschneidenden Dammes der Posen-Kreuzburger Bahn stehen bis zu 140 Jahren alte Eichen, auch Fichten, Birken und Erlen. Unter den mächtigen Eichen und Kiefern wächst reiches Unterholz, besonders aus prunus padus, evonymus, ulmus-Arten, sambucus, corylus, an den Rändern und in den Lichtungen aus cornus,

1) Wir verdanken diese Angabe einer freundlichen Mitteilung des Herrn Oberforsters Teske in Ludwigsberg. Danach ist die irrtamliche Angabe in den O. M., Maiheft 1908 S. $78 \mathrm{za}$ berichtigen.

7) Diese und einige folg. Angaben entnehmen wir dem Berichte aber Baume u. Walder der Prov. Posen von Prof. Dr. Pfuhl (Zeitschr. der Naturw. Abt. der Deutschen Gesell. für Kunst u. Wiss. in Posen, X. Jahrgang 1904, sowie XVI. Jahrg. 1909. 
prunus spinosa, rhamnus, crataegus u.s. w. bestehend. Zwischen den Büschen rankt reichlich bumulus lupulus. Da der Auwald forstlich nicht ausgenützt wird und nur tote Bäume entfernt werden, so bietet er allerlei Vögeln, besonders den Sängern erwünschte und reichliche Brutgelegenheit. Stark verschilfte Lachen im Walde selbst wie an seinen Rändern, ebenso auch die die Warthewiesen bis zur Stadt bin durchziehenden Altwässer gewähren dem Wassergeflügel gute Verstecke. Die Wiesen selbst sind ziemlich dürftig. Das Warthetal wird alljährlich mehr oder weniger überflutet, ja bei Hochwasser ganz ausgefüllt. Dabei wird der sehr durchlässige Sand je nach den Bodenverhältnissen teilweise umgelagert. Wo er nicht geradezu Dünen bildet, kann im Bereich der regelmälsigen Überschwemmungen jedenfalls nur äufserst wenig Humus entstehen, so dafs das dürftige Gras nur in nassen Jahren eine leidliche Heuernte gibt. Entlegenere Stellen sind etwas besser daran, so dafs wir neben Standorten von arabis arenosa und oenothera biennis alle Übergänge bis zu denen von symphytum officinale finden.

Am rechten Ufer der Warthe, die hier nahe an die Uferböben herantritt, befinden sich mehrere Lehmausstichtümpel mit Rohrhorsten (phragmites communis), die Rohrsänger beherbergen und von Schwalben und Bachstelzen zur Nachtruhe aufgesucht werden. Diese Tümpel sind ein Produkt der Ziegeleien, die den hier nicht eben tief liegenden tertiären Ton, den sogenannten Posener Flammenton, verarbeiten. Etwa dem Viktoriapark gegenüber befindet sich in einem Lehmausstiche alljährlich eine starke Brutkolonie von Erdschwalben (c). Die Brutröhren werden in den oberen Diluvialsanden angelegt.

In Posen selbst und seiner nächsten Umgebung waren es besonders die prächtigen Festungsanlagen (auch die Wallgräben, die jetzt meist verschwunden sind, boten noch vor wenigen Jahren der Kleinvogelwelt, besonders Blaukehlchen und Sperbergrasmücken, günstige Plätze), der im Weichbilde der Stadt liegende Petrikirchhof, die Kirchhöfe hinter dem neu angelegten Schillerparke mit seinem schönen Teiche, sowie der nahe an der Stadt liegende Schilling mit seinen stattlichen alten Bäumen, die reiche Ausbeute versprachen und boten. Berühmt sind besonders seit alter Zeit die Anlagen unsres Kernwerks wegen ihres Reichtums an Nachtigallen. Das Kernwerk, ein Teil der Stadtbefestigung, der sich steil aus dem Warthe- und Bogdankatale erhebt, enthält einen zwar nicht sehr breiten, aber etwa $4 \frac{1}{2} \mathrm{~km}$ langen Gebüschgürtel, bei dem im Sommer durch chelidonium, geum urbanum, galium aparine, myrrhis temula und urtica der Boden fast meterhoch dem Blick entzogen wird.

Unterhalb Posens bekleidet die Ufer der Warthe stellenweise dichtes Weidengebüsch, das leider immer mehr gelichtet oder auch völlig ausgerottet wird. Doch beherbergt das Ufergebüsch an der gegenüber dem Schilling einmündenden Cybina 
sowie am rechten Wartheufer bis zur Militärfähre bin noch zahlreiche Grasmücken, auch Rohrsänger, Blaukeblchen u.s. w. Unterhalb der Fähre treten auf der rechten Stromseite sandige Uferhöhen bis unmittelbar an den Flufs, so dafs bei Hochwasser sich einige Meter hohe, glatte Absturzstellen bilden, an denen in manchen Jahren zahlreiche Erdschwalben nisten (a). Zu einer dritten Kolonie (b) führt die hier die Warthe mittels einer Fähre kreuzende Ringstrafse. Diese Schwalbensiedelung befindet sich etwa $1 \mathrm{~km}$ westlich in einer vor dem Dorfe Naramowice liegenden Sandgrube.

Einige $100 \mathrm{~m}$ unterhalb der Fähre wendete sich früher die Warthe nach Nordwest, durchströmte das hier sich etwas verengende Tal und wurde dann durch steile Uferhöhen wieder in die nördliche Richtung gedrängt. Hier fallen schroffe Abhänge ins Warthtetal ab, deren Nordende die sogenannte "tertiäre Wand" (vgl. Pfuhl u. a. O.) bildet. Durch die Geradlegung des Warthebettes ist hier, da die stagnierende alte Warthe an der ehemaligen Stromseite stets Wasser zu führen flegt, eine bei normalem Wasserstande allerdings stets zugängliche Insel geschaffen worden. Nicht nur auf dieser Insel, sondern auch in dem alten Warthebette wächst dichtes Weidengebüsch, zwischen dem einzelne kleine Tümpel, von üppig aufgeschossenen Grasbüscheln umsäumt, frei bleiben. Da ferner auch das linke Ufer des ehemaligen Warthebettes dichtes Weidengebüsch (bes. Mandel- und Purpurweide) trägt, zwischen dem Gräser und Nesseln wuchern, Brombeeren und Hopfenptlanzen ranken, da ferner das vorher genannte Steilufer, auf dem der Weg zum Etablissement Wolfsmühle führt, mit schier undurchdringlichem Schwarz- und Weifsdorngebüsch bedeckt ist, so ist hier die Kleinvogelwelt recht zahlreich vertreten. Grasmücken, Rohrsänger, Blaukehlchen, Fitislaubvögel, Rohrammern sind in auffallender Menge vorhanden. Auch der Heuschreckensänger fehlt nicht, und regelmälsig haust hier die Zwergrohrdommel.

Mit Recht wird von Pfuhl auch die Anmut des Landschaftsbildes hervorgehoben. Während von der "tertiären Wand" aus der Blick nach Norden hin ungehemmt nach dem etwa $5 \frac{1}{2} \mathrm{~km}$ entfernten, mit dunkeln Kiefern gekrönten Annaberge schweift, nach Süden hin mit Wohlgefallen auf den Türmen des Doms und den aus dem GründerGärten hervorlugenden Häusern derUnterstadt ruht, schiebt sich geradeaus gegen die sandigen Höhen des Gluwnoer Exerzierplatzes hin ein dunkles Kiefernwäldchen, das militärische Schiefsstände enthält, vors Auge und schliefst das Landschaftsbild nach Osten hin wirkungsvoll ab. Dieser Kiefernwald ist der bevorzugte Schlafplatz aller bei uns überwinternden Saatkrähen und Doblen; auch Mantelkrähen fehlen nicht, die sich jedoch meist von den andern getrennt halten. Auf den Sandflächen unterhalb des Wäldchens bausen Triele. Weidengebüsch in grölserer oder geringerer Ausdehnung begleitet auch weiterhin unterhalb der: Wolfsschlucht das linke Ufer der 
Warthe bis zum Knie (dem Dorfe Czerwonak gegenüber), und besonders der letate Teil des hier ziemlich breiten Tales enthält mehrere mit dichtem Schilf und hohen Sumpfgräsern bewachsene Lachen, die Enten, Bläfsköpfe, Teichhühnchen beherbergen und in der Zugzeit gern von Sumpfschnepfen und Totaniden besucht werden.

Schmäler sind die Täler, die sich die Cybina und Bogdanka gegraben haben, doch liegen hier die Verhältnisse ähnlich wie beim Warthetale. Das dichte Buschwerk an der Elsenmühle $\left(4^{1} / 2 \mathrm{~km}\right.$ etwa von Posen entfernt) beherbergt Turteltauben. Die hohen sandigen Ufer, auf denen Triele wohnen, bilden einen lebhaften Kontrast mit dem saftigen Grün der Büsche und der ausgedehnten Wiesen, die weiter unterbalb das Flüfschen rechts und links umsäumen, teilweise unterbrochen durch kleinere odergröfsere Waldparzellen, von denen das Solatscher Kiefernwäldchen, etwa $17 \mathrm{ha}$ grols, in den Besitz der Stadt Posen übergegangen ist. Die rührige Stadtverwaltung ist eifrig dabei, durch schöne Parkanlagen eine anmutige Verbindung zwischen Stadt und Wald berzustellen; auch ausgedehnte Teichanlagen sind in der Nähe des an der Bogdanka unterhalb Solatsch liegenden Auwäldchens geschaffen worden. In diesem Wäldchen, das freilich infolge der neuen Anlagen stark gelichtet ist, konnten wir besonders Sperbergrasmücken, doch auch zuzeiten zahlreiche andere Vögel, die nach den Früchten der hier reichlich wachsenden Weichselkirschen (prunus mahaleb) lüstern waren, beobachten.

Besonders tief eingeschnitten ist stellenweise das sich von Posen aus in ōstlicher Richtung binziehende 'Tal der Cybina. Etwa $1 \mathrm{~km}$ vor dem Warschauer Tore liegt am rechten Cybinaufer das Etablissement Schlofspark Ostend unmittbar an dem hier teichartig erweiterten Flüfschen. Die dichten Rohrbestände und die Schilfmassen auf den teilweise schwimmenden Inseln werden von Sumpf- und Wassergeflügel belebt. Gegenüber dem Schlofspark Ostend ziehen sich an der Schwersenzer Chausee entlang militärfiskalische Schiefsstände hin, in deren prächtigen Anlagen zahlreiche Vögel wohnen. Hinter den Schieĺsständen auf den sandigen rechten Uferböhen befindet sich die Brutstätte eines Trielpaares, während die Wiesenflächen jenseits des Flülschens vomWiesenpieper, Kiebitz, Braunkehlchen und zeitweilig vom Heuschreckensänger bewohnt werden. Weiter aufwärts treffen wir auf einen der lieblichsten Punkte in der Umgegend unserer Stadt. Es ist der sogenannte Kobylepoler Grund. Während das Flülschen bei der Lonczmühle wieder eine von undurchdringlichem Röhricht bedeckte teichartige Erweiterung bildet, die von zahlreichen Vögeln belebt wird, sind die Ufer sowie die steilen Gehänge mit Laubwald und dichtem Buschwerk bewachsen, das sich auf den Uferhöhen in einem Kiefern- und Birkenwäldchen fortsetzt. Das zwischen steilen Uferhöhen tief eingeschnittene Tal zieht sich, an einer Seite von dichtem Buschwerk umsäumt, flufsaufwärts an dem etwa $5 \mathrm{~km}$ 
von Posen entfernten Park von Kobylepole vorbei bis zu der das Flüfschen überschreitenden Chaussee nach Schwersenz. Östlich der Strafse nimmt der von der Cybina durchströmte Schwersenzer See fast das ganze Tal ein. Dieser See, etwa 90 ha grofs, ${ }^{1}$ ) das Posen zunächst liegende grölsere Wasserbecken, ermangelt zwar „der landschaftlichen Reiz verleihenden Waldbedeckung", zeigt aber an seinen Rändern fast durchweg eine dichte Rohr- und Schilfwand, die sehr zahlreichen Rohrsängern, besonders Drossel- und Teichrohrsängern, Unterkunft bietet, während die Wasserfläche von Haubentauchern belebt wird.

Dies ist das Gebiet, auf das sich während einer Reihe von Jahren unsre Beobachtungen erstreckten. Wir waren so ziemlich täglich draufsen, freilich nicht immer auf ausgedehnten Exkursionen, wenn solche auch so oft als möglich gemacht wurden. Von Berufsgeschäften sehr in Anspruch genommen, mufsten wir unsre täglichen Spaziergänge für unsre $Z$ wecke fruchtbar zu machen suchen. Eine merkbare Lücke ergibt sich nur für die Zeit der Sommerferien, wo wir unserem Beobachtungsgebiete fern wares.

Nur in wenigen Fällen baben wir über das vorher skizzierte Gebiet hinausgegriffen, wenn entweder eigene Beobachtungen in anderen Teilen der Provinz unserseits gemacht worden waren (Zwergfliegenfänger), oder bestimmte Mitteilungen dritter Personen vorlagen.

Eingehendere Beobachtungen über den Herbstzug der Vögel sind erst in den letzten beiden Jahren von uns angestellt worden. Auf Angaben in der Literatur haben wir hier, wo es sich um eigene Beobachtungen handelt, grundsätzlich nicht Bezug genommen. In der systematischen Aufzählung der Vögel und ibrer Benennung halten wir uns durchaus an Reichenow „Die Kennzeichen der Vögel Deutschlands", Neudamm 1902.

\section{Calymbus cristatus L.}

Für die nähere Umgebung von Posen ist der Haubentaucher nur ein seltner Durchzugsvogel, da gröfsere Wasserflächen nicht vorhanden sind. Am 17. IV. 09 wurde I Stück auf den überschwemmten Wiesen zwischen Schilling und Gluwno beobachtet; etwas weiter entfernt, doch mit dem Glase noch erreichbar, waren 2 weitere Stücke sichtbar. Die, Vögel befanden sich noch auf dem Frühjahrszuge.

Am 18. IX. 05 hatte sich gegen Abend ein Vogel dieser Art auf der Warthe gegenuiben dem Rennplatz in einem stillen Winkel zwischen einer Buhne und dem rechten Ufer niedergelassen. 
Der Vogel schwamm unruhig hin und her, flog aber nicht ab, als wir vorbeigingen.

Auf dem etwa $10 \mathrm{~km}$ von Posen entfernten Schwersenzer See brütet diese Art. Am 28. VI 08 waren in einer Schilfbucht 2 Paare alter Haubentaucher sichtbar, von denen das eine 2, das andere 1 halbwüchsiges Junges bei sich hatte. In der Nähe der Zieliniec-Mühle am Westende des Sees war ein drittes Paar mit 2 Jungen sichtbar, an der Schilfwand hinziehend. Auch auf dem Lubascher See im Kreise Czarnikan ist diese Art häufiger Brutvogel. An 14. IV. 08 waren diese Taucher hier bereits reichlich vertreten (H.).

Am 19. X. 09 waren pfeifende Rufe junger Taucher, die sich offenbar auf dem Zuge befanden, auf der schilfbedeckten, teichartig erweiterten Cybina beim Etablissement Schlolspark Ostend zu hören. Ob die Urheber dieser Töne junge Haubensteifsfülse oder Rothalstaucher waren, konnte bei der zum Verwelchseln ähnlichen Beschaffenheit der Rufe beider Arten nicht festgestellt werden.

Anmerkung: Vgl. über die Rufe der Jungen beider Arten Hesse im J. f. O. 1908 I p. 26 und 1909 III, dessen Angaben nach Beobachtungen in Tütz in Westpreulsen, wo beide Arten ziemlich häufig brüten, durchaus bestätigt werden konnten (H.).

\section{Colymbus nigricans Scop.}

Am 2. V. 08 börten wir Balztriller des kleinen Tauchers auf einer von dichtem Weidicht umsäumten Überschwemmungslache in der Nähe der Wolfsmühle, ebenso am 8. V., später jedoch nicht mehr. Obwohl gute Verstecke und ausreichender Pflanzenschutz vorhanden waren, scheinen die Vögel nicht zur Brut geschritten zu sein, vielleicht wegen ungenügenden Wasserstandes. Am 17. V. waren Balztriller etwas weiter nördlich auf einem der gras- und schilfreichen Überschwemmungstümpel zwischen Wolfsmühle und Wartheknie zu hören. Auch bei niedrigem Wasserstande trocknen diese Tümpel nicht aus, bieten auch durch den üppigen Pflanzenwuchs an den Rändern genügenden Schutz; der kleine Wasserspiegel ist meist mit den Blättern der Seerose bedeckt. Vielleicht hatten sich die Vögel zum Brutgeschäft hierher gezogen, doch wurden Nest und Junge nicht gefunden.

Am 26. IV. 09 wurde dieser kleine Taucher auf der teilweise mit Rohr und Schilf bedeckten teichartig erweiterten Cybina an der Loncz-Mühle gehört. Nach zuverlässigen Angaben verweilt der Vogel hier den ganzen Sommer, so dafs auch hier mit dem Brüten des Vogels zu rechnen ist.

Auf dem Herbstzuge wurde der $\mathrm{Z}$ wergtaucher nur einmal beobachtet. Am 12. Xl. 05 trillerte ein solcher in der gute Deckung bietenden Westecke des sogenannten Rohrteichs, des 
Ausschachtungsgeländes an der Südseite des Kernwerks. Das Gelände, im Sommer eine Wiese, war erst vor wenigen Tagen durch Ableitung der Bogdanka überflutet worden, um im Winter als Eisbahn zu dienen.

\section{Larus ridibundus L.}

Im März oder im April treffen regelmälsig einzelne Stücke oder kleine Schwärme dieser Möwenart hier ein und treiben sich eine Zeitlang auf den überschwemmten Wiesen oder über der Warthe umher. Am 22. III. $08 \mathrm{zog}$ ein kleiner Schwarm gegenüber dem Schilling wartheaufwärts; am 28. III. 09 schwebte 1 Stück über den Wiesen an der Einmündung der Cybina in die Warthe, von einer Saatkrähe mehrfach befehdet. Am 17. und 18. IV. 09 trieben sich anf den noch immer überschwemmten Wiesen 2 wischen Schilling und Wolfsmühle zahlreiche Vögel dieser Art umher; am Nachmittage des 18. IV. erhob sich unter lebhaftem Geschrei ein Schwarm von etwa 10 Stück, um weiter zu ziehen.

Auch im Juni wurden wiederholt einzelne Vögel über der Warthe gesehen; am 5. VI. 081 St. in der Nähe des Wartheknies, über dem Flusse auf und ab streichend; am 4. VI. 09 1 St. über der Warthe an der Insel hinzieheud um $1 / 28 \mathrm{p}(1 / 28 \mathrm{p}$ (= post meridiem) $=1 / 28$ Uhr nachmitttags); am 6. VI. zog 1 St. um $6 \mathrm{p}$ flufsaufwärts bis zum Schilling, dann wieder stromabwärts; um 1/27 $p$ flogen 2 St. ziemlich hoch jenseits der Warthe der Stadt zu; am 29. VI. wurde 1 Vogel gegen Abend von der Wolfsmühle aus beobachtet, die Warthe aufwärts fliegend, gegen $1 / 29 \mathrm{p}$ war der Vogel wieder bei der Wartheinsel.

Im Frühjahr 1907 versuchte ein Paar Lachmöwen sich hier an der Warthe anzusiedeln. Am 30. V. kam uns in der Nähe der Überschwemmungslachen zwischen Wolfsmühle und Wartheknie ein Vogel, ängstlich käck - - - - rufend, entgegengeflogen und verfolgte uns unablässig mit seinem Geschrei. Wir versuchten von den Uferhöhen des Warthetales einen Überblick über das Sumpfgebiet zwischen den Lachen zu gewinnen und entdeckten denn auch leicht das brütende Weibchen, dessen leuchtendes Weils sich scharf von dem Grün der Umgebung $a b h o b$, an einer für uns leider unzugänglichen Stelle. Es war nur ein Pärchen dieser Vögel vorhanden. Der Versuch scheint mifslungen zu sein; jedenfalls wurde er in den folgenden Jahren nicht wiederholt.

\section{Mergus merganser L.}

Im Spätherbst des Jahres 1897 wurde auf der Jagd ein schönes altes $\sigma^{7}$ an der Warthe in der Nähe des Dorfes Czerwonak erlegt. Der verwundete Vogel spie mehrere Gründlinge aus, die soeben erst erbeutet sein mufsten. Leider wurde das Stück nicht erhalten. 


\section{Nyroca fuligula L.}

Am 14. IV. 08 weilte eine einzelne Reiberente auf dem Lubascher See (Kreis Czarnikau). Am 17. IV. 09 trieb sich ein Schwarm von 6 Stück auf den überscbwemmten Wiesen westlich von Gluwno umher; die Vögel waren sehr scheu.

\section{Anas boschas L.}

Die Stockente ist hier noch ein ziemlich häufiger Brutvogel, da sie sicb in die Verbältnisse zu schicken weils und selbst mit ganz kleinen Gewässern vorlieb nimmt. Sie wurde brütend gefunden auf dem Ausstichsumpfe vor dem ehemaligen Wildator (am 30. VI. 07 eine Ente mit 12 halberwachsenen Jungen sichtbar), auf den Altwassern im Eichwalde (12. V. 08 eine Alte mit 4 etwa anderthalb Wochen alten Juugen sichtbar), auf und an den Utberschwemmungslachen zwischen Wolfsmühle und Wartheknie (am 17. V. 08 wurde in einem überjährigen Lupinenfelde ein Nest mit 10 Eiern gefunden, von dem die Alte abstrich), ja sogar auf dem alten Petrikirchhofe zwischen Halbdorf- und Ritterstrafse. Am 19. IV. 06 wurde hier auf dem kleinen etwa 30-40 Schritt langen und 10 Schritt breiten, jetzt abgelassenen Tümpel ein Stockentenpaar beobachtet. Am 8. V. sals die Ente auf einem winzigen mit einigen Rohrstengeln besetzten Inselchen auf dem Neste, ebenso am 13. V. um 9 a (= ante meridiem, Vormittags). Auch der Erpel war auf dem Tümpel, flog aber bei unsrer Annäherung erschreckt ab. Am 31. V. sals die Ente nicht auf dem Neste, bielt sich aber in der Nähe auf; auch am 7. VI. war die Ente auf dem Tümpel, doch nicht auf dem Neste, das offenbar wegen fortgesetzter Störung verlassen war. Das Nest war jedes Schutzes entblörst, da die Ente beim Verlassen desselben die es umgebenden Rohrhalme zum Bedecken herabgezogen hatte.

Am 18. IV. 07 wurde auf demselben Tümpel wieder ein Paar Stockenten gesehen. Am 28. V. batte die Ente kleine Dunenjunge um sich, die offenbar in dem Gebüsch in der Nähe des Tümpels erbrütet worden waren. Die Alte verschwand mit ihren Jungen unter einem überhängenden Busche; es waren 13 Stück. Am 3. VI. führte die Ente nur noch 2 Junge, am 8. VI. nur noch eins; die übrigen waren augenscheinlich weggefangen worden, wie das niedergetretene Gras und die zertrampelten Nesselbüsche am Rande des Tümpels anzeigten. Selbst die Ruhe des Friedhofs hatte die Brut des Vogels nicht zu schützen vermocht. Das eine ihr verbliebene Junge brachte die sorgsame Entenmutter auf; sie harrte geduldig bei ihm aus, denn fortführen, wie es die Enten gerne tun, konnte sie es nicht, ja sie wurde so zutraulich, dals sie sich füttern liels. Was für ein prächtiges Familienbild hätte es gegeben, wenn sie im Besitze ihrer 13 Kinder geblieben wäre. Am 3. IX. war das Junge noch auf dem Tümpel unter der Obhut der Mutter. 
Auch am 7. V. 08 wurde wieder ein Enterich dieser Art auf dem Tümpel beobachtet, ebenso am 14. V., doch scheint die Ente dieses Jahr hier nicht gebrütet zu haben, oder sie wurde ihrer Eier beraubt, oder sämtliche Junge wurden weggefangen; jedenfalls waren am 6 . VI. die Nesselbüsche am Tümpel vollständig zertreten. Am 18. VI. wurde auf dem im Jahre vorher angelegten Teiche des Schillerparks eine Stockente mit 6 Jungen beobachtet. Die Vögel waren ziemlich vertraut; sie wurden wenig belästigt, da sie der in der Nähe wohnende Parkwärter unter seine Obhut genommen hatte. Auch im Jahre 1909 hat eine Stockente in der Nähe des Schillerparks unter einem Busche gebrütet. Der brütende Vogel liefs sich auf dem Neste vom Parkwärter füttern.

Am 1. IX. 09 wurde gegen Abend auf dem vor dem Eichwalde infolge reichlicher Erdausschachtungen entstandenen ziemlich ausgedehnten Tümpel ein ganz weifses Stück, das mit einem zweiten normal gefärbten Stücke aufging, erlegt. Das Tier war völlig weils, nur einige Oberschwanzdeckfedern zeigten einen dunklen bis schwarzen Saum; Ruder und Schnabel waren gelbrot, Augen dunkelbraun. Das Stück war hier schon mehrfach in einem Schoof angetroffen worden; es war augenscheinlich ein junges Tier. Wie uns unser Amtsgenosse Prof. Heimer mitteilte, hat er im vergangenen Jahr ebenfalls ein ganz weifses Stück dieser Art auf der Feldmark von Stutendorf, Eisenbahnstation Ketsch, geschossen.

\section{Anas penelope L.}

Am 5. IV. 08 wurden auf den Überschwemmungslachen zwischen Wolfsmühle und Wartheknie 4 Paare Pfeifenten beobachtet, die sich sehr scheu und vorsichtig zeigten.

\section{Anas querquedula L.}

Neben boschas ist dies die häufigste Entenart bei Posen, da sie sich auch mit kleinen Tümpeln und Lachen begnügt. Am 14. IV. 04 waren etwa 8 St. auf dem Altwasser zwischen Viktoriapark und Eichwald.

Am 20. VI. 07 trieb sich auf der Lache am Südrande des Eichwaldes eine Knäkentenfamilie umher. Die Entin verliels das Wasser und ging auf den Schwaden des abgemähten Grases dem Insektenfange nach, wobei sie eifrig ihre Jungen rief. Da diese dem Rufe nicht folgten, flog sie wieder ins dichte Schilf zurück. Auch auf den Überschwemmungstümpeln zwischen Wolfsmühle und Wartheknie brütete diese Art regelmäfsig. Am 5. IV. 08 flogen 2 Paar ab, wobei die $\sigma^{\top} \sigma^{\top}$ lebhaft knarrten (klerreb), auch am 8. V. und 17. V. und am 20. V. wurden hier einige St. beobachtet, am 4. VIII. zeigte sich auf einer der Lachen ein Schoof von 6 jungen Enten. Am 1. V. 08 flog auch von einem der 
Tümpel der faulen Warthe vor der Insel ein Pärchen dieser Ente mit knarrendem klerreb ab.

Am 28. VIII. 08 wurden 17 St. dieser Art auf dem Ausstichtümpel vor dem Eichwalde gezählt, die auch zum Teil in der Folgezeit hier Nahrung suchten, die sie hier offenbar reichlich fanden, wie auch eine zeitlang Stockenten und zahlreiche Totaniden offenbar der ihnen zusagenden Nahrungsverhältnisse wegen hier verweilten, bis wiederholte Eingriffe seitens der Menschen den Überlebenden den Aufenthalt daselbst verleideten.

\section{Anser sp.}

Am 18. III. 07 zogen Scharen wilder Gänse über das Netzbruch bei Guhren, Kr. Czarnikau; am 22. II. 08 flog über das Schillingstor hinweg eine Schar von 25 St., lebhaft rufend, von Südwest nach Nordost. Die Flugordnung wurde wiederholt unterbrochen, schliefslich ordneten sie sich in 3 Schleifen zu 9 und je 8 Stück.

Der Herbstzug erfolgte im Oktober: am 16. X. 07 zogen Gänse überhin nach Westen; am 27. X. um $1 / 49$ p ein Schwarm, lebhaft rufend. Am 4. X. 09 zogen um 3 p 26 Wildgänse beim Dorfe Guhren (Kreis Czarnikau) über dem Netzetal von Ost nach West; am Tage vorher waren in diesem Jahre hier die ersten in derselben Richtung ziehenden Gänse, 13 St., bemerkt worden (Mitteilung des Lehrers J. Jany in Guhren).

\section{Charadrius hiaticula L.}

Am 24. IV. 04 weilten 5 Regenpfeifer auf den sandigen Uferhöhen der Cybina jenseits der militärfiskalischen Ringstrafse (auf dem Gelände befinden sich heute Kirchhöfe) lebhaft tlya tlya lill lill lill lill lill schreiend; aus einiger Entfernung war ein $r$ in dem Paarungsrufe börbar. Die Vögel, die nahe an sich herankommen liefsen, bildeten auf dem Boden fast einen Knäuel und trieben einander, gebärdeten sich dabei aber keineswegs stürmisch, machten vielmehr einen sanften Eindruck. Gröfse (etwa Drosselgrölse), Gesang und Zeichnung (breites Brustband) wiesen entschieden auf den Sandregenpfeifer hin. Die Vögel wurden in der Folgezeit nicht wieder gesehen.

\section{Charadrius dubius Scop.}

Der Flufsregenpfeifer ist ein regelmäfsiger Besucher gewisser Lokalitäten in der Umgebung Posens und brütet hier auch. Ankunftszeiten: 28 . IV. $04 ; 18$. V. 06; 22. IV. 07; 3. V. 08; 11. V. 09.

Am 30. V. 08 trieben sich an den sandigen Ufern des Ausstichtümpels gegenüber den militärischen Schiefsständen vor dem Warschauer Tor mehrere Vögel dieser Art (8-10 St.) umher, 
lebhaft etwa tli tli tyl tyl tyl rufend. In ihrer Gesellschaft befand sich ein Totanus littoreus, der, von der allgemeinen Fröhlichkeit angesteckt, gleichfalls neben seinen Locktönen einen Balzruf hören liefs, der wie tewí tewi tewi -- klang. Die Vögel waren augenscheinlich noch auf dem Zuge.

Am 23. V. 06 rief ein Regenpfeifer recht ängstlich in dem von dichtem Weidengebüsch umgebenen sandigen Bett der alten Warthe oberhalb der Wolfsmühle. Wir legten uns auf die Lauer, und bald erschien der Vogel etwa 30 Schritt vor uns und liefs sich zum Brüten auf seinem Neste nieder. Die 4 Eier lagen auf dem blofsen Erdboden an einer Stelle, an der von der Frühjahrsüberschwemmung zurückgebliebener Schlamm infolge der Dürre geborsten war und an den Bruchstellen sich ein wenig nach oben umgebogen und so eine kleine natürliche Vertiefung gebildet hatte, die dem Vogel vollauf genügte.

Am 29. V. 07 wurde ein Pärchen dieser Vögel auf den Sandaufschüttungen vor dem ehemaligen Eichwaldtore beobachtet, das auch am 10. VI. sichtbar war, also wohl hier gebrütet haben dürfte.

Im Jahre 1908 brütete ein Paar an dem vorher genannten Ausstichtümpel hinter dem Bahnhof Warschauer Tor. Die Vögel wurden hier mehrfach im Mai und im Juni gesehen und am 16. VI. neben den beiden Alten, die sich sehr ängstlich gebärdeten, auch 4 flügge Junge beobachtet, ebenso am 25. VI.

In demselben Jahre hatte ein Paar auf den Ödfächen der Uferhöhen der Cybina hinter den militärischen Schiefsständen Junge erbrütet, die seit dem 21. VI. hier einige Zeit hindurch beobachtet wurden.

Auch im Jahre 1909 brütete hier ein Paar, das am 11. V., 14. V., 7. VI. und 15. VI. beobachtet wurde. An dem letztgenannten Tage zeigten sich die Alten sehr ängstlich; am 19. VI. waren 4 und am 22. VI. 5 St. sichtbar. $A b$ und $z u$ liefsen die Vögel neben ihrem gewöhnlichen Rufe eine Reibe von Tönen hören, denen der Lockruf zweimal angehängt wurde: tli tli tli tli tli diü diü.

Aufserdem wurden Vögel dieser Art beobachtet in der Nähe der Badestelle oberhalb des Krzyžanowskischen Holzplatzes (18. V. 06; 13. V. 08), an dem Ausstichtümpel vor dem Eichwalde (21. VI. 09 um 9 Uhr $p$, ebenso am 28. VI. um $3 / 410$ p lebhaft rufend: tli tli tli tli tli trlü trlü trlü), an den Lehmstichen an der Schneidemühler Bahn in der Nähe von Solatsch (27. VI. 09) und zwischen Wolfsmühle und Wartheknie (am 29. VI.).

Auf dem Abzuge befanden sich jedenfalls die Vögel, die am 21. VIII. 09 gegen $8 \mathrm{Uhr}$, am 22. VIII. gegen Abend (je 1 St., also wohl an beiden Tagen derselbe Vogel), am 29. VIII. und am 4. IX. sich an dem Ausstichtümpel vor dem Eichwalde durch ihre Rufe bemerkbar machten; am letztgenannten Termine waren hier auch 2. St. sichbtar, seitdem keine mehr. 


\section{Vanellus vanellus L.}

Ankunftszeiten: 7. III. 03; 24. III. 04; 16. III. 05; 25. III. 06; 11. III. 07; 7. III. 08 (Meldung aus der Provinz); 15. III. 08. (bei Posen); 27. III. 09 (um 5 Uhr p ziehen zuerst 5 Kiebitze, dann ein einzelner über Starolenka binweg, auffallenderweise von Nordost nach Südwest; die Warthewiesen sind seit morgens 11 Uhr völlig überschwemmt).

Es waren zunächst immer nur kleine Schwärme oder einzelne Paare, auch wohl einzelne Vögel (am 11. III. 07 wurde ein Vogel, auf den dem Schilling gegenüberliegenden Wiesen bei Schneegestöber auffiegend, von einigen Krähen belästigt, die nach ihm stielsen), die an den angegebenen Terminen beobachtet wurden. Grölsere Massen folgten in der Regel erst später nach, die dann einige Zeit auf den teilweise überschwemmten Wiesen $\mathrm{zu}$ verweilen pflegten. So hatte sich am 18. III. 08 ein starker Schwarm gegenüber dem Viktoriapark niedergelassen. Da kam plötzlich ein Sperberweibchen, von einer Mantelkrähe heftig verfolgt, daher und versetzte die Vögel in grofse Aufregung. Der ganze Schwarm ging hoch, vielfach schreiend, ein Totanus totanus rief warnend sein djü djü djü dazwischen, und die Aufregung legte sich erst, als der Sperber längst unserm Gesichtskreise entschwunden war.

Am 20. III. 08 lag dem Rennplatze gegenüber ein starker Schwarm auf den Wiesen. Um $3 / 46 \mathrm{p}$ erhob sich wie auf Kommando ohne ersichtlichen Grund die ganze Schar unter vernehmlichem Brausen (es waren mindestens $75 \mathrm{St}$.), um in nordöstlicher Richtnng weiterzuziehen. Noch grölsere Schwärme wurden am 17. IV. 09 auf den Warthewiesen westlich von Gluwno beobachtet, unter denen sich lebhaft rufende Rotschenkel tummelten. Einige der Vögel jagten sich neckend mit Lachmöwen umber. Die Kiebitze setzten gegen Abend ihre Reise fort.

Die Zahl der Brutpaare in der Umgebung Posens scheint sich nach dem Grade der Bewässerung der in Betracht kommenden Stätten zu richten. Regelmälsig brüteten die Vögel in wenigen Paaren an der Cybina bei Johannistal und in gröfserer Anzahl an den Lachen zwischen Wolfsmüble und Wartheknie. An letztgenannter Stelle brüteten im Jahre 1908 etwa 5 bis 7 Paare. Ende Juni waren die Jungen erwachsen. Zablreicher als sonst waren Kiebitze im Jahre 1909 hier als Brutrögel zurückgeblieben, da infolge der ausgiebigen Frühjahrsüberschwemmung viel Wasser auf den Warthewiesen zurückgeblieben war. An den Lachen vor dem Wartheknie nisteten 8-10 Paare, mehrere Paare an dem Ausstichtümpel vor dem Eichwalde, 1 Paar vor der Wartheinsel und 2 Paare auf den Cybinawiesen bei Johannistal.

Am 29. VI. hatten Alte und Junge ihre Brutstellen vor dem Wartheknie verlassen, um auf den Feldern umherzustreichen, wie das ja andere Brutvögel nach glücklicher Beendigung ihres 
Brutgeschäfts auch $z u$ tun pflegen. Wochenlang war hier in diesem Jahre von Kiebitzen nichts zu sehen und zu hören. Da traf am 10. VIII. der erste Schwarm von 12 St. ein und verweilte längere Zeit an dem Ausstichtümpel vor dem Eichwalde. Am 18. VIII. riefen mehrere abends auf den Feldern oberhalb des Tümpels; am 21. VIII. um 8 Uhr p wieder am Tümpel; am 22. flogen 7 Kiebitze, von einem den Sumpf durchwatenden Kaaben aufgescheucht, in Begleitung mehrerer Bruchwasserläufer in südwestlicher Richtung ab, auch am 27. zog von bier ein Schwarm von 30 St. gen Südwest um $51 / \mathrm{k}$. Am 1. IX. waren daselbst $8 \mathrm{St}$. sichtbar, zum Teil in Gesellschaft von Rotschenkeln. Am 2. IX. wurde unterhalb der Wolfsmühle ein Scbwarm von 40 St. beobachtet, und am 8. IX. lagen hier auf einem Sturzacker westlich der Warthe 50 bis 75 St., die sich bei unsrer Annäherung nach Norden wendeten, also augenscheinlich dem Laufe der Warthe folgten. Eine halbe Stunde später folgte eine Schar von 9 St. und hielt dieselbe Richtung. Am 12. IX. wurde ebendort ein Schwarm von $19 \mathrm{St}$. gesehen. Die letzten Kiebitze (7 St.) wurden ebendaselbst am 19. IX. beobachtet. Die Vögel flogen, nachdem sie eine Weile gerastet hatten, um $1 / 26 \mathrm{p}$ direkt nach 0 sten.

\section{Oedienemus oedicnemus L.}

Der Triel ist in der Umgegend von Posen nicht selten und konnte auch als Brutvogel festgestellt werden. Der Vogel wurde mehrfach gesehen und gehört auf den sandigen Feldern am rechten Ufer der Bogdanka zwischen der Elsenmühle und dem Bahndamme der Eisenbahn Posen-Kreuz (z. B. am 18. V. 03) und auf den sandigen Uferhöhen der Cybina hinter den militärischen Schiefsständen vor dem Warschauer Tor, wo er sich gegen Abend durch sein lautes krärlith bemerkbar machte (am 1. V. 09 um $1 / 28$ p) und im Jahre 1909 auch brütete. Auch von den Sandfeldern des Gluwnoer Exerzierplatzes her war sein Ruf am 11. V. um $71 /$ s mehrfach zu hören.

Am 6. V. 07 erhielten wir aus der Forst Streitort an der Gluwna ein Gelege des Triels, das bei einer militärischen Übung gefunden worden war. Die beiden Eier befinden sich in der Sammlung der hiesigen Berger-Oberrealschule.

Als wir uns am 7. VI. 09 um $8 \mathrm{Uhr} p$ von der LonczMühle her den Schiefsständen vor dem Warschauer Tor näherten, flog ein Stück ohne Laut vor uns auf, ebenso am 15. VI. um 71/4 p. Der Vogel kehrte auffälligerweise wieder um, warf sich in einiger Entfernung zur Erde, flog dann wieder auf, und liefs sein krärlith hören. Das Verhalten des Vogels liefs auf eine Brut schliefsen, und in der T'at fanden wir nach einigem Suchen auf der teilweise mit Borstengras bewachsenen Ödfäche in der Nähe der militärfiskalischen Ringstrafse in einer flachen, selbstgescharrten Vertiefung neben einem Stäudchen Graphalium divoicum das 
Gelege vou 2 Eiern. Wir bezeichneten uns die Stelle in unauffälliger Weise, da die Eier nicht leicht zu entdecken waren, trotzdem sie fast ganz frei dalagen, und revidierten von Zeit zu Zeit das Nest. Am 19. VI. flog der Vogel wie gewöhnlich 20-30 Schritte vom Neste entfernt auf, nachdem er uns bis auf 75 Schritte batte herankommen lassen. Er hatte, da er uns nicht sehen kounte, zweifellos infolge der Warnrufe eines Charidrius dubius rechtzeitig das Nest verlassen. Als wir uns am 22. VI. gegen Abend dem Neste näherten, flog der Vogel wie sonst auf, rief jedoch dieses Mal mehrmals und gebärdete sich ängstlicher als vorher. Die Nestmulde war leer, von Eierschalen nichts $\mathrm{zu}$ bemerken. Die Jungen schienen jedoch irgendwo in der Nähe zu stecken, denn ein alter Vogel erschien unter wiederholten Rufen, warf sich unfern der Ringstralse nieder und verschwand laufend im Unkraut. Wir gingen ihm absichtlich nicht nach, um nicht Vorübergehende aufmerksam zu machen, sondern wendeten uns den Schiefsständen zu. Da wurde ein zweiter Vogel sichtbar und suchte uns fortzuleiten, indem er sich, freilich immer in ziemlicher Entfernung, zur Erde warf, eine Strecke rannte und wieder aufflog, welches Manöver er mehrmals wiederholte. Auch am 26. waren die beiden Alten wiederholt sichtbar, doch hielt sich der eine Vogel, wohl das Männchen, stets etwas entfernter. Neben krärlith hörten wir von ihnen ein klagendes tih oder tüih oder auch tië (absinkend). Nach erneutem Absuchen der Umgebung des Nestes fand sich um 8 Uhr $p$ ein Junges, das regungslos zwischen einigen Stauden des Borstengrases sals, den Kopf mit dem ziemlich kräftigen Schnabel vorgestreckt, so dals es in seinem weifsgrauen Gewande einem Steine sehr ähnlich sah. Es machte, als wir nahe herantraten, keinen Fluchtversuch, liefs sich vielmehr ruhig aufheben, wobei es kräftig mit den Beinen strampelte. Das fette, quabbelige Ding war etwa von Haubenlerchengrölse, oben ganz mit kurzer, grauer Dunenwolle bedeckt. Über den Kopf wie über den Rücken liefen zwei schmale, dunkelbraune Streifen; auch die Flügelchen zeigten eine dunkle Zeichnung. Der schon ziemlich kräftige Schnabel war an der Wurzel graugrün, spitzewärts schwarz. Es blieb ruhig an der Stelle sitzen, an der es niedergesetzt wurde. Das zweite Junge war nicht sichtbar.

Gegen Ende August schienen die Vögel umherzustreichen. Am 21. VIII. rief einer um $81 / 2$ Uhr $p$ an der Südseite des Eichwaldes, wo er sonst nicht gehört worden war. Am 23. VIII. 09 wurde ein Paar auf der Feldmark von Stutendorf (Bahnstation Ketsch) gesehen.

\section{Tringa alpina L.}

Am 24. IX. 08 verweilten an der Freibadestelle vor dem ehomaligen Eichwaldtore 5 Alpenstrandläufer im Winterkleide Die Vögel, die sehr vertraut waren, liefsen sich bis auf 5 Schritte angehen; sie wurden hier mehrere Tage hindurch gesehen. 


\section{Tringoides hypoleucos L.}

Ankunftszeiten: 28. IV. 04 (Freibadestelle vor dem ehemaligen Eichwaldtore, 1 St.); 18. V. 06 (an der Warthe gegenüber dem Rennplatze, 1 St.); 6. V. 07 (vor dem ehemaligen Eichwaldtore, 1 St.); 30. IV. 08 (an der Warthe vor dem Eichwalde, 4 St.); 15. V. 09 (gegenüber dem Rennplatze, mehrere St.).

Auch über die angegebenen Termine hinaus wurde der Flufsuferläufer nicht gerade selten in unserm Gebiete beobachtet: Am 23. V. 06 trieben sich Uferläufer an dem schlammigen Ufer der alten Warthe bei der Insel umber, und am 13. V. 08 wurde auf einer kleinen Schlammbank gegenüber dem Viktoriapark der Paarungsruf oder Balzgesang des Uferläufers gehört, der aus einer hellen viersilbigen mehrmals wiederholten Strophe besteht: titihidi etc.; die dritte Silbe ist stärker betont als die andern. Es war danach zu vermuten, dals der Vogel in unserm Beobachtungsgebiete brütete. Diese Vermutung wurde später zur Gewilsheit. Am 26. VI. 08 liefs an dem sandigen, von kleinen Schlammbänken unterbrochenen Ufer der Warthe am südöstlichen Teile des Eichwaldes ein Vogel dieser Art mebrmals ein warnendes hiht hören (auch zweisilbig hiht hiht). Der Vogel sals auf einer Buhne. Nur durch einen schmalen sandigen Rain von der Warthe getrennt, dehnt sich hier eine Uberschwemmungslache mit teils grasigen, teils schlammigen Ufern aus, an denen zum Teil, der Warthe zugekehrt, Weidenbüsche stehen. Hier war das Nest zu vermuten. Es wurde zwar nicht gefunden, doch trieb sich hier wie an der nahen Warthe einige Tage später und auch im Juli und bis in den August binein (noch am 2. und 6. VIII. an der Warthe beobachtet) regelmä(sig eine Familie von $6 \mathrm{St}$. umher, die zweifellos hier beheimatet war. Auch an der Wartheinsel wurde in der Brutzeit (20. V. 09) ein Pärchen dieser Vogelart beobachtet.

Auf dem Herbstzuge befanden sich wohl schon mehrere Vögel dieser Art, die am 15. VIII. 08 an der Warthe unterhalb der Wolfsmühle gesehen wurden. Zu ihnen hatte sich ein Vogel von ziemlich dunkler Färbung, dik dik rufend, gesellt. Ob Waldwasserläufer? Auch später noch wurden Flufsuferläufer mehrfach beobachtet: am 29. VIII. 08 an der Warthe vor dem Rennplatze 1 St., ein zweites in der Nähe der Badestelle; am 4. IX. mehrere Vögel am rechten Wartheufer gegenüber dem Viktoriapark, lebhaft rufend; am 8. IX. 09 am rechten Ufer der faulen Warthe 1 St., das sich mehrmals weitertreiben liels, dann aber wieder zurückflog. Die Vögel verweilen gern an der Wartheinsel, da die Weidenbüsche Deckung bieten und die etwas schlammigen Ufer der alten Warthe erwünschte Weideplätze gewähren. Etwas weiter nordwärts war ein zweites St. zu sehen, dafs mehrmals sein hididi hören liels. Am 10. IX. waren hier ebenfalls Vögel dieser Art zu hören und gegen Abend 2 St. sichtbar. Auch am 12. IX. wurden hier noch 3 Vögel gesehen. Am gleichen Tage rief um $1 / 27 \mathrm{p}$ 
1 St. mehrmals an der Einmündung des Vorflutgrabens in die Warthe.

\section{Totanus totanus L.}

Angehörige dieser Art, sowie überhaupt alle Totaniden wurden hier nur unregelmäfsig beobachtet. An ausgedehnteren Überschwemmungstümpeln fehlten sie in der Regel nicht; herrschte dagegen Wassermangel, so blieben die Vögel selbstverständlich aus, indem sie unser Beobachtungsgebiet überflogen.

Am 18. IIl. 08 trieb sich ein einzelnes St. dieser Art unter einem starken Schwarme von Kiebitzen laut rufend auf den überschwemmten Warthewiesen westlich des Viktoriaparks umher (vgl. oben p. 395); desgleichen am 21. III. 091 St. in Gesellschaft zahlreicher weifser Bachstelzen auf den Cybinawiesen am Berdychowoer Damm, Nahrung auf den vereisten Wiesen suchend. Im Abfiiegen rief er mehrmals tü (Tauwetter, $+5^{\circ}$, bedeckter Himmel). Am 17. IV. 09 befanden sich zahlreicheVögel auf den übersch wemmten Wiesen westlich von Gluwno.

Auch im Mai wurde der Vogel mehrmals beobachtet: am 21. V. 06 am Ketscher See; am 26. V. 07 an der Cybina oberhalb von Kobylepole (Balzgesang!), am 30. V. 07 an einer der Überschwemmungslachen vor dem Wartheknie.

Der Herbstzug begann im Jahre 1909 (früher nicht beobachtet!) bereits im August. Vom 22. dieses Monats an waren regelmäfsig Totanusarten an dem ausgedehnten, aber flachen Erdausschachtungstümpel vor dem Eichwalde zu sehen, unter denen sich Vögel unsrer Art besonders dadurch bemerkbar machten, dafs sie bis an den Bauch ins Wasser hinein- und darin herumwateten: am 22. VIII. 1 St. unter zahlreichen Bruchwasserläufern und einigen hellen Wasserläufern, am 24. VIII. $6 \mathrm{St}$. Um $1 / 26 \mathrm{p}$ erhoben sich 6 Tot. totanus und $5 T$. littoreus und zogen laut pfeifend nach Südwest davon. Am 27. VIII. waren wieder $6 \mathrm{St}$. von unserer Art sichtbar, am 28, an einer Stelle 4 St., doch waren offenbar mebr Vögel vorhanden, da von einer andern Seite Rufe herübertönten. Daneben gab es heute nur Bruchwasserläufer, keinen littoreus. Am 29. VIII. standen um 5 Uhr p 8 St. im seichten Schlammwasser, teilweise die Schnäbel unter den Flügeln. Die Vögel liefsen sich ziemlich nahe angehen, erhoben sich dann aber und flogen in südwestlicher Richtung davon. Auch am 1. IX. wurden hier mehrere Rotschenkel beobachtet, die aber bald abzogen. Beunruhigung seitens des Jagdpächters und teilweise Zuschüttung des Sumpfgeländes hatte zur Folge, dals die Vögel den Platz mieden. Am 4. IX. zog ein St. gegen Abend über den nahen Eichwald hin, am 7. IX. ebenso, laut rufend, 1 St. über den Rennplatz. Am 19. IX. zog 1 St. dieser Art um $1 / 26 \mathrm{p}$, djü djü rufend, in der Nähe des Wartheknies fursabwärts. Auch am 30. IX. war noch eine Totanusart hörbar, die über die Wartheinsel in boher Luft hinwegzog. 


\section{Totanus ochropus L.}

Der Waldwasserläufer wurde mit Sicherheit nur einmal auf dem Frühjahrszuge beobachtet: am 17. IV. 07 flogen 2 Vögel dieser Art von den überschwemmten Warthewiesen westlich von Gluwno ab, die im Weiterziehen mehrmals ein lautes tuit ti ti ti hören lielsen.

\section{Totanus littoreus L.}

Auf dem Frühjahrszuge wurde der Helle Wasserläufer am 8. V. 08 (1 St. an einer Lache unterhalb der Wolfsmühle Nahrung suchend) und am 8. V. 09 beobachtet. An dem letzteren Termine wurden 6 St. an den Lachen $z$ wischen Wolfsmühle und Wartheknie gesehen; die Vögel waren ziemlich scheu. Ein verspätetes Exemplar trieb sich noch am 30. V. 08 an dem flachen Ausstichtümpel links der Schwersenzer Chaussee (gegenüber den Schielsständen) umher unter einer Schar rufender und trillernder Flufsregenpfeifer (vgl. oben p. 394). Vielleicht war der Vogel identisch mit dem unter dem 8 . V. 08 beobachteten Stück. Freudig erregt mit den Regenpfeifern hin- und herfliegend, liefs er nicht nur eifrig sein tü tü oder tjü tjü hören, sondern übte auch fleilsig seinen lieblich klingenden Balzgesang: tewí tewi tewi etc. Doch scheuer als die andern, flog er bei unsrer Annäherung in östlicher Richtung davon.

Der Herbstzug begann im Jahre 1909 (vorher nicht beobachtet!) am 22. VIII., an welchem Tage sich 2 St. unter zahlreichen Bruchwasserläufern und Kiebitzen an dem Ausstichtümpel vor dem Eichwalde durch ihre Rufe bemerkbar machten. Auch 1 Rotschenkel tummelte sich unter der Schar. Die Vögel liefsen sich bis auf etwa $30 \mathrm{~m}$ angehen. Um $3 / 47 \mathrm{p}$ waren alle $\mathrm{ab}-$ gezogen. Auch am 21. VIII. hielten sich hier mehrere Vögel dieser Art unter Rotschenkeln auf, ebenso am 27. VIII. An diesem Tage waren 5 St. zu sehen. Die Vögel erhoben sich um 5 Uhr p unter lebhaften Rufen und flogen in südwestlicher Richtung davon. Weitere Beobachtungen wurden hier leider aus den oben (p. 393 u. 399) angegebenen Gründen vereitelt.

\section{Totanus glareola L.}

Am 8. V. 09 trafen wir 18-20 Vögel dieser Art an den in diesem Jahre infolge der ausgiebigen Frühjahrsüberschwemmung besonders zahlreichen Überschwemmungslachen $z$ wischen Wolfsmühle und Wartheknie. Die Vögel, die wenig scheu waren, gingen meist paarweise auf, und nur die einzelnen Pärchen schienen enger zusammenzuhalten. Im Abfliegen liefsen sie mehrere kurze, hintereinander ausgestofsene Töne hören, wie gi oder ki oder ti ti ti ti ti (5 bis 6 mal) klingend, doch hörte man auch im Sitzen von ihnen ein trillerndes di di di di di. Im Fluge trugen 
sie öfters eine Art Balzgesang vor, der eine auffallende Ähnlichkeit mit einer Strophe der Heidelerche batte und etwa wie didel didel didel didel didel klang.

Der Herbstzug begann am 21. VIIl. Abends um 8 Uhr hörten wir an dem schon mehrmals erwähnten Ausschachtungstümpel vor dem Eichwalde die lebhaften Rufe von Bruchwasserläufern (ti ti - - ), in die sich einmal der oben angegebene Balzgesang mischte. Da die Vögel nicht mehr zu sehen waren, so gingen wir ihnen am folgenden Tage (22. VIII.) nach und fanden hier nachmittags um $1 / 25$ Uhr 15 bis 20 St. Drei St. zogen mit 5 Kiebitzen ab; die übrigen schienen grölstenteils noch vor Abend mit hellen Wasserläufern und Rotschenkeln fortgezogen zu sein, denn um $3 / 47$ Uhr börten wir nur $1 \mathrm{St}$. rufen. Am 24. VIII. waren 7 St. sichtbar, die bald laut ti ti pfiffen, bald auch ein leiseres gif hören liefsen, während ein St. den Balzgesang übte. Auch am 27. und 28. VIII. waren Vögel dieser Art hier zu beobachten. Am 29. trafen wir einen Schwarm von einigen 20 St., die sich jedoch bei der Nahrungssuche über den Sumpf zerstreut hatten und im schlammigen, seichten Wasser herumwateten. Kurz nach 5 Uhr erhob sich ohne ersichtlichen Grund der ganze Schwarm, flog einige Male in reilsendem Fluge hin und her, um dann wieder einzufallen. Dahei waren kurze Unterbaltungstöne zu hören wie trit oder trie oder trüi. Auch am 1. IX. waren reichlich Bruchwasserläufer hier vorhanden, daneben Rotschenkel und Kiebitze. Da infolge Zuschüttung und Austrocknung die Wasserfläche sich erheblich verringert hatte, auch mannigfache Störungen eintraten, so mieden in der Folgezeit die Vögel zu unserm Bedauern den Platz.

\section{Numenius arquatus L.}

Der Vogel wurde im Frühjahr gelegentlich auf den Netzwiesen unweit Czarnikau beobachtet, so am 18. III. 07 und am 14. IV. 08 bei dem Dorfe Guhren (Kreis Czarnikau). Im ersteren Falle waren es mehrere St., die einander lehhaft zuriefen, im letzteren ein einzelner Vogel, der, lebhaft tloih tloih twi twi twi rufend, sich mehrmals auftreiben liefs und sich, wie das bei dieser Art immer der Fall ist, sehr vorsichtig zeigte. Das Brüten des Vogels konnte leider nicht mit Sicherheit festgestellt werden.

Auch in dem folgenden Falle muls mit dem Brüten des Vogels gerechnet werden. Als wir am 11. VI. 07 von Kosten aus, wo wir auf der Sprossersuche waren, uns in der Nähe des Forsthauses Neu-Kurzagura den Obrawiesen näherten, kam uns, lebhaft rufend, ein Keilhaken entgegengeflogen. Der Vogel kam aus den Bruchwiesen, zog in respelstvoller Entfernung an uns vorüber und liefs sich dann auf einem sandigen Hügel in der Nähe eines Roggenfeldes am Rande des Bruches nieder. 


\section{Gallinago gallinago L.}

Die Bekassine wurde hier auf dem Frühjahrszuge nur selten beobachtet. Die in Betracht kommenden Stellen werden offenbar von den Vögeln meist überflogen, weil in der Zugzeit die Warthewiesen grörstenteils überflutet sind. Erst nach dem Zurückweichen der Wassermassen wurde am 8 . V. 09 ein verspätetes St. an einer Überschwemmungslache zwischen Wolfsmühle und Wartheknie gesehen.

Den bekannten Balzlaut der Bekassine haben wir hier nie vernommen, doch war er in den achtziger Jahren des vorigen Jahrhunderts auf den Bruchwiesen in der Nähe der Königl. Forst bei Wongrowitz (beim sog. Eierhäuschen) nicht selten zu bören. Die Vögel dürften dort gebrütet baben. $\mathrm{Ob}$ dies heute noch der Fall ist, ist uns unbekannt.

Ziemlich häufig wurden auf dem Herbstzuge Vögel dieser Art sowohl oberhalb als besonders unterhalb Posens an den Altwässern betroffen, so dafs wohl angenommen werden kann, dafs der Zug der Bekassine im Herbste der Richtung des Flusses folgt. Im verflossenen Jahre (1909), auf das sich unsre Aufzeichnungen beschränken, trafen wir den ersten Herbstvogel am 9. VIII. vor der Wartheinsel, wo sich die Vögel auch in der Folgezeit gern an den von dichtem Weidengebüsch umsäumten Tümpeln der faulen Warthe aufhielten. Auch an dem mehrfach genannten Ausschachtungstümpel vor dem Eichwalde wurden mehrere Tage hindurch Bekassinen beobachtet. Am 22. VIII. wurden hier $2 \mathrm{St}$. von einem in dem seichten Wasser herumwatenden Knaben herausgestofsen; am 24. rief $1 \mathrm{St}$. um $1 / 27 \mathrm{p}$ über dem Eichwalde, um 7 Ubr flogen 4 St. von dem Tümpel ab, mehrmals ihren charakteristischen Ruf hören lassend, von denen 1 St. wieder dorthin zurückkehrte.

Am 8. IX. wurde 1 Stück an der Wartheinsel gesehen, ebenso an den folgenden Tagen bis zum 12. IX. je $1 \mathrm{St}$., wohl immer das gleiche. Es liefs sich, da es durch Weidenbüsche gedeckt war, ganz nahe angehen. Am 15. IX. wurden hier 4 St., am 19. gegen Abend $5 \mathrm{St}$. beobachtet, ebenso am 20., wohl dieselben Vögel. Am 25. IX. wurdeu 2 St. gesehen, am 30. IX. 3 St., am 13. X. 4 St., am 15. X. 2 St., am 16. X. 4 oder 5 St., am 18. $X$. 7 St., auf die einzelnen Tümpel der faulen Warthe verteilt. Die Vögel flogen meist paarweise ab. Am 24. X. war 1 St. ebendort, und auch am 30.X. wurde hier noch ein einzelnes St. angetroffen, das um $41 / 4 \mathrm{p}$ laut rufend abflog. Vom 25. IX. bis 13 . X. wurden auch $z$ wischen Wolfsmühle und Wartheknie mehrmals $1-3$ St. beobachtet und am 21. IX. und 29. IX. 2 und 1 St. oberhalb Posens an einer Lache vor dem Rennplatze gesehen.

\section{Gallinago gallinula $\mathrm{L}$.}

Am 20. III. 09 wurde 1 St. dieser Art aus dem Dorfe Luban, südlich des Eichwaldes, dem Gymnasialzeichenlehrer Gandert 
eingeliefert, dafs sich an den Drähten der Eisenbahn totgeflogen hatte.

\section{Scolopax rusticola L.}

Im März 1908 wurden im Eichwalde 3 Waldschnepfen erlegt (Mitteilung des stud. vet. Nitsche); im Frühjahr nach einer Angabe des Försters wegen des Hochwassers kein Schnepfenzug.

\section{Otis tarda L.}

Am 3. XI. 07 wurde auf der Feldmark von Stutendorf (Bahnstation Ketsch) eine Herde Trappen (etwa 30 St.) gesehen, die sich jedoch nicht schulsmärsig angehen lielsen (Mitteilung von Professor Selting und Professor Heimer). Auch im Herbste des Jahres 1908 waren nach derselben Quelle daselbst Vögel dieser Art zu sehen.

\section{Grus grus L.}

Auf dem Zuge wurden Kraniche hier mehrfach beobachtet, im Frühjahr auch paarweise, leider wurden darüber keine Aufzeichnungen gemacht.

Brutvogel ist der Kranich in der Landgrabenniederung zwischen Zaborowo und Tharlang, Kreis Lissa i. P. Am 13. VI. 09 wurde hier ein Paar aus geringer Entfernung beobachtet. Revierförster Stabl gab an, dafs in seinem Revier (Forstrevier Tharlang, zur Herrschaft Reisen gehörig) in diesem Jahre 4 Paare dieser Vögel brüteten, von denen 1 Paar 3 Junge hatte; die Tiere sind nach einer weiteren Angabe ,schon immer dagewesen". (Mitteilung des Gerichtssekretärs H. Miller in Lissa vom 18. VII. 09). Auch in der Nähe des Forsthauses Niewerder bei Schönlanke ist der Kranich regelmälsiger Brutvogel (S.). Beide Brutplätze werden schon von Baer (0. Monatsschr. XXXII No. I S. 7 ff.) aufgeführt.

\section{Rallus aquaticus L.}

Im Juli des Jahres 1905, also wohl noch in der Brutzeit, wurde das scharfe "wuit" der Wasserralle auf den Warthewiesen oberhalb Posens gegen Abend gehört. Wir gingen dem Rufe nach und wurden an eine sehr schilfige Lache unweit des Rennplatzes geführt. Obwohl wir dicht an den Rand des kleinen Gewässers traten, liefs sich der Vogel, der durch das dichte Pflanzengewirr so gedeckt war, dafs wir ihn nicht bemerken konnten, durchaus nicht stören. Der Ruf war recht weit hörbar. Auch am 12. VI. 08 wurde das "wuit" der Ralle vernommen, das aus einer Lache, die sich, stark verschilft, einige $100 \mathrm{~m}$ am Renuplatze hinzieht, herübertönte.

\section{Crex crex L.}

Der Wachtelkönig erscheint hier in manchen Jahren erst recht spät. So wurde im Jahre 1903 sein knarrender Ruf erst 
am 23. V. gehört. Als Ankunftszeiten wurden weiterhin notiert: 11. V. 06 (in der Nähe der Wartheinsel); 11. V. 07 (ebendort), 17. V. 08 (in einem Klee- und Grasfelde unterhalb der Wolfsmühle); 13. V. 09 (auf der Wartheinsel).

In den letzten beiden Jahren war der Vogel bei Posen entschieden häufiger vertreten, und es ist nicht daran zu zweifeln, dals er hier Brutvogel ist. Er wurde in der Brutzeit im Jahre 1908 beobachtet: am 1. VI. 1 St. auf der Wiese vor der Wartheinsel; der Vogel erhob sich ohne ersichtlichen Grund, jedenfalls ohne dals wir ihm zu nahe gekommen wären, aus der Wiese, strich etwa $20-30 \mathrm{~m}$ niedrig fort und warf sich dann wieder ins Gras; am 12. VI. 1 St. auf den Wiesen vor dem Rennplatze; am 16. VI. auf den Cybinawiesen zwischen Schlofspark Ostend und der militärfiskalischen Ringstralse 2 St., jenseits der Ringstrafse 1 St. An demselben Tage zählten wir auf den Warthewiesen oberhalb Posens 3 St. Am 19. VI. auf den Bogdankawiesen zwischen dem Auwäldchen und der Ringstrafse 2 St. Am 2. VII rief 1 St. in einem Haferfelde hinter der Gärtnerei in Unterwilda, wohin es sich von den kahlen Wiesen gezogen hatte. Am 20. V. 09 wurden auf den Wiesen zwischen Schilling und Wartheknie 5 St. gezählt, und auch den andern Örtlichkeiten fehlte der Vogel in diesem Jahre nicht.

Auf dem Herbstzuge wurde die Wiesenralle nur einmal beobachtet und zwar gegen Fnde September 09. Am 25. dieses Monats flog ein Vogel dieser Art um $1 / 25$ p unmittelbar vor unsern Fülsen aus dem niederen Weidicht vor der Wartheinsel heraus. Es war seit vielen Wochen kein Wiesenknarrer mehr bemerkt worden. Die hier heimischen Vögel machen sich offenbar, sobald die Jungen erwachsen sind, sofort auf die Reise.

\section{Ortygometra porzana L.}

Am 25. V. 06 wurde uns ein toter Vogel dieser Art aus Gluwno überbracht. Am 18. IX. 09 wurde ein Tüpfelsumpfhuhn am Glacis zwischen Gluwno und Bromberger Tor gefunden, das an den Telegraphendrähten der Posen-Gnesener Bahn verunglückt war. Es zeigte Verletzungen an der Brust und an einem Flügel. $\mathrm{Um}$ dieselbe Zeit wurden einem hiesigen Vogelhändler 2 St. eingeliefert, von denen das eine tot, das andere beschädigt war.

\section{Gallinula chloropus L.}

Diese Art ist auf den zahlreichen verschiliten Lachen im Überschwemmungsgebiete der Warthe nicht selten, erscheint jedoch hier meist erst, wenn das Hochwasser sich verlaufen und sich ausreichender Pflanzenschutz gebildet hat, so am 6. V. 07 auf der Lache in der Nähe des Eichwaldrestaurants (dieser Vogel liefs am 27. V. folgende Rufe hören: kurr; wik tük tük; wykkekkekkek; er wurde hier auch am 23. VI. gehört und am 29. VI. gesehen), 
am 13. V. 08 auf der Lache am Südrande des Eichwaldes, wo der Vogel sich auch am 16. V. durch sein krühk bemerkbar machte. Bieten alte Rohrbestände oder Weidengebüsch ausreichenden Schutz, so treibt das Teichühnchen hier schon früher auf den kleinen Wasserflächen zwischen dem Röhricht und Buschwerk sein Wesen. So wurde es am 26. IV. 09 im Kobylepoler Grunde beobachtet, am 27. IV. im Weidicht vor der Wartheinsel, ebenso am 13. V. und 20. V., am 1. V. auf der teichartig erweiterten Cybina an der Lonczmühle und am 11. V. am Schlofspark Ostend. Manchmal zeigt sich das Hühnchen recht zutraulich. Am 20. VI. $07 \mathrm{kam}$ ein Teichhuhn von der Lache am Südrande des Eichwaldes zweinal ans Ufer und lag auf dem abgemähten Grase eifrig dem Insektenfange ob. Es hatte in dem Pflanzengewirr der Lache offenbar Junge, die zwar nicht sichtbar wurden, auf deren Vorhandensein man aber aus dem Nicken und Schwanken der Pflanzen schliefsen mufste. Halbwüchsige Junge sahen wir am 17. VI. 07 auf einem der Tümpel der alten Warthe oberhalb der Wolfsmühle, und am 28. VI. 08 trieb sich ein Junges ad. an der Lonczmühle $z$ wischen den breiten Blättern von nuphar luteum umber, ohne sonderliche Scheu zu zeigen. Ebenso wurden erwachsene Junge dieser Art (2 St.) auf einer Lache am Nordrande des Eichwaldes beobachtet.

Die Teichhühnchen scheinen sich bei uns früh auf die Wanderung zu begeben oder, gelegentlich der Entenjagd beunruhigt, andere Örtlichkeiten aufzusuchen, denn im September bekommt man den Vogel schon recht selten zu Gesicht. Am 8. IX. 09 trafen wir 1 St. auf einer kleinen, nur an 2 Seiten etwas Pflanzendeckung bietenden Lache vor dem Wartheknie (an der Kehle weifs, die Stirnplatte sehr klein, kaum zu sehen, anscheinend gelblichgrün, der Schnabel gelbgrün); am 30. IX, verweilte der Vogel noch dort. Bei unsrer Annäherung versteckte er sich in dem dürftigen Schilfe; herausgescheucht, schwamm das Tierchen kopfnickend auf der Mitte der Lache umher, tauchte weder, noch dachte es daran fortzufliegen, pickte vielmehr mit dem Schnabel häufig ins Wasser, als ob es Nahrung aufnähme.

\section{Futica atra L.}

Bläfshühner sind hier seit 1905 regelmälsig alle Jahre auf den zahlreichen Lachen und der teichartig erweiterten Cybina an der Lonczmühle und am Ostendpark beobachtet worden, doch wegen des Frühjahrshochwassers selten in der eigentlichen Zugzeit. Sie suchen dann solche Stellen auf, wo sie noch einige Deckung finden und stellen sich dann meist erst im Mai auf ihren Brutplätzen ein. Am 24. III. 08 trafen wir auf der Lache am Südwestrande des Eichwaldes 1 St., das sich in einem Klumpen Genist, den das Hochwasser um die überhängenden Zweige eines Baumes aufgehäuft hatte, ein verstecktes Plätzchen 
gesucht hatte. Der Vogel liefs sich bis auf wenige Schritte angehen, ruderte dann eilig fort, kehrte aber sofort wieder um, als wir uns entfernten. Am 30. III. sahen wir mehrere BläIshühner in dem einige Deckung bietenden Weidicht an der Wartheinsel.

Als Brutvogel wurde das Blälshuhn festgestellt auf der faulen Warthe oberhalb der Wolfsmühle (im Juli 1905 waren hier 6 junge Blälsköpfe s ichtbar; am 14. v. 07 konnten wir auf dem Rohrteich in der Nähe der alten Warthe, da die Rohrstoppeln nur geringe Deckung boten, 2 Vögel auf den Nestern sitzen sehen), auf einer Lache vor dem Wartheknie (am 2. V. 082 Paare sichtbar), auf der Lache am Südrande des Eichwaldes (1 Paar; am 21. VIII. 08 mit Jungen), auf dem Mühlteich der Lonczmühle (am 28. VI. 08) und am Schlofspark Ostend (8. VIII. 08 erwachsene Junge sichtbar). Im September scheint bereits der Abzug vor sich 2u gehen. Am 21. IX. 09 wurde noch 1 St. auf der Lache links vom Eingange zum Eichwalde gesehen.

\section{Ciconia ciconia L.}

Der weilse Storch ist in der näheren Umgebung Posens schon recht selten geworden; nur einen bis zum vorigen Jahre regelmäfsig benutzten Horst vermögen wir anzugeben. Er befindet sich in dem nahen Dorfe Rataj, war jedoch im letzten Jahre unbesetzt.

Auch auf dem Durchzuge ist der Vogel jetzt eine Seltenheit, während er im letzten Jahrzehnt des vorigen Jahrhunderts noch ziemlich häufig angetroffen wurde. Die Wiesen diesseits des Eichwaldes (Rennplatz) tragen im Volksmunde noch heute den Namen Storchwiesen (Bociankawiesen, von bocian pol.=Storch). Am 5. 1V. 06 flog 1 St. um 10 a über Unterwilda ziemlich niedrig der Warthe zu; am 12. V. 09 flogen um $1 / 28$ p 4 Störche von Nordost nach Südwest, bogen dann über den Aufschüttungen zwischen Wilda- und Eichwaldtor nach Süden um und schlugen die Richtung nach den Warthewiesen ein. Am 21. V.: 1 St. zwischen Schlofspark Ostend und Ringstrafse Nahrung suchend; am 27. V.: 3 St. auf einem Saatfelde rechts der Eichwaldstrafse.

\section{Ardetta minuta L.}

Die Zwergrohrdommel ${ }^{1}$ ) war in einzelnen Jahren bier nicht eben selten, in andern nur spärlich vertreten. Sie erschien in der Regel in der ersten Hälfte des Mai. Am 13. V. 06 war der Paarungsruf dieses kleinen Reihers, ein gedämpftes quurg oder quorg, das, mit dem Unkenruf keineswegs zu vergleichen, einige Ähnlichkeit mit dem quoar des Teichfrosches hat, im dichten

1) Vgl. B. "Die Zwergrohrdommel in der Umgegend von Posen" in der Zeitschr. "Aus dem Posener Lande" 1909 No. 7. 
Weidicht vor der Wartheinsel zu hören. Zwischen den einzelnen Rufen war eine Pause von 3-4 Sekunden. Als wir die Zweige auseinanderbogen, um nach dem Urheber zu forschen, flog 1 St. $\mathrm{ab}$ und setzte sich etwa $150 \mathrm{~m}$ weiter auf einen Weidenbusch. Später wurde hier ein zweites St. beobachtet. Am 23. V. waren 2 Vögel - augenscheinlich ein gepaartes Paar - zu sehen, ebenso an derselben Stelle am 31. V. $O b$ es zn einer Brut gekommen ist, konnte nicht mit Bestimmtheit festgestellt werden.

Auch im folgenden Jahre (1907) liefs hier am 11. V. 1 St. seinen Paarungsruf hören. Wir näherten uns behutsam der Stelle und sahen den Vogel an der gegenüberliegenden Seite eines Tümpels in einer Entfernung von 25-30 Schritt $11 / 2 \mathrm{~m}$ hoch auf einem Weidenzweige sitzen. Der Vogel sals, als er uns erblickte, still und stocksteif und bequemte sich erst zum Abfliegen, als wir laut wurden.

Am 8. V. 08 war der Paarungsruf wieder an der nämlichen Stelle zu hören. Es wurde festgestellt, dafs das quurg, so gedämpft es in der Nähe erklingt, doch unter günstigen Verhältnissen bis auf 100 Schritt und darüber von einem geübten Ohre zu vernehmen ist. Die ersten Rufe wurden um $6^{35} \mathrm{p}$ gehört, am 17. $\nabla$. jedoch schon um $41 / 2 \mathrm{p}$ und wieder um $71 / 4$. Ein zweites Stück rief um $3 / 47 \mathrm{p}$ in dem dichten Weidicht auf der Wartheinsel gegenüber der Einmündung des von der Wolfsmühle herabkommenden Mühlbachs. Am 19.V. wurde derselbe Paarungsruf in dem eine Überschwemmungslache umsäumenden dichten Weidengebüsche zwischen Cybinamündung und Eisenbahndamm unfern der Militärschwimmanstalt gehört, am 30. V. auch aus dem mit Erlen durchsetzten Rohrdickicht am Schlofspark Ostend und zwar um $1 / 25 \mathrm{p}$.

Im Jahre 1909 wurde hier nur 1 St. beobachtet, der Paarungsruf überhaupt nicht gehört. Das genannte St. flog am 8. V. eine Strecke über dem Weidicht vor der Wartheinsel hin und warf sich dann ins Gebüsch. Am 20. . war es wieder sichtbar; es war noch unausgefärbt, also jedenfalls ein vorjähriger Vogel. Dieses St. trieb sich hier den ganzen Sommer über umher, immer allein. Es wurde mehrfach beobachtet, zum letzten Male am 4. VIII. nachmittags um 4 Uhr und wieder abends um 7 Uhr. $\mathrm{Zu}$ der letztgenannten Zeit sals der Vogel in einer Entfernung von etwa 50 Schritt auf einem grölseren Weidenbusche etwas unterhalb des Wipfels, durch ein Wasserloch von uns getrennt, und liefs sich durch unser Rufen nicht verschenchen.

\section{Ardea cinerea L.}

Am 21. IX. 09 zogen 2 St., mehrfach ihren heiseren Schrei ausstofsend, über den Eichwald hinweg.

Ein Reiberstand von ungefähr 50 Nestern befindet sich auf den hohen Kiefern der kleinen und grolsen Reiherinsel im 
Klossowskisee bei Zirke, Kreis Birnbaum (mitgeteilt am 14. VI. 09 von Prof. Dr. Pfuhl).

In den 80er Jahren des vorigen Jahrhunderts nistete der Fischreiher ziemlich reichlich auf den hohen Eichen der königl. Forst bei Wongrowitz.

\section{Columba palumbus L.}

Wenn auch die Ringeltaube in der Hauptsache ein Waldvogel ist, so sind doch auch hier einige Fälle zu verzeichnen, in denen es der Vogel verstanden hat, sich an den menschlichen Verkehr anzupassen und sogar inmitten der Stadt an einem belebten Orte zu brüten. Nach einer Mitteilung des Mittelschullehrers Kupke vom 8. IV. 07 hat etwa 3 Jahre vor dem angegebenen Datum auf einer hohen Kastanie des Petrikirchhofs wiederholt eine Ringeltaube genistet, und im Jahre 1905 brütete ein Paar im Krasnohauland bei Moschin in unmittelbarer Nähe des Wirtshauses auf einer Linde und brachte Junge auf, die freilich verspeist wurden, worauf dann natürlich die alten Vögel nicht wiederkehrten.

In den Anlagen unsres Kernwerks nistete regelmälsig 1 Paar dieser Vögel, so am 24. IV. 08 auf einer Kiefer westlich des Pulverhauses. Hier machte sich der Tauber auch am 19. V. durch sein Rucksen bemerkbar. Der Eichwald beherbergt in der Regel 2 oder 3 Brutpaare. Nicht nur am 2. VII. 08 wurde hier das Rucksen des Taubers an 2 Stellen gehört, sondern auch noch am 6. VIII. Am 18. IX. schols daselbst der stud. Nitsche eine junge Ringeltaube. Auch im Jahre 1909 waren im Eichwalde mindestens 2 Brutpaare vorhanden. Am 18. VIII. waren 4 Stück, wohl junge Vögel, auf der Lichtung an der Südseite des Eichwaldes sichtbar.

\section{Columba oenas L.}

In unserm Eichwalde wurden Hohltauben, trotzdem Brutlöcher überaus reichlich vorhanden sind, nie beobachtet. Gelegentlich eines Besuches des Buchenwaldes bei Boguniewo (Oberförsterei Eckstelle) zwecks Beobachtung des Zwergfliegenschnäppers wurde diese Taubenart dort festgestellt.

\section{Turtur turtur L.}

Die Turteltaube ist bei Posen wiederholt beobachtet worden, wenn auch nicht ganz so häufig wie die Ringeltaube, so am 28. IV. 04 in dem Fichtendickicht südlich des Forsthauses; ebendort am 15. VI. 07; am 13. VI. 08 an 3 Stellen in der Nähe der Elsenmühle im Bogdankatale (hier machte 1 Stück von einer bohen Fichte aus eine Art Balzflug, wobei es eifrig rief); am 21. VI. 08 im Kobylepoler Grunde; am 6. V. 09 im Gehölz bei Solatsch. Am 9. VI. wurde 1 St. in dem Wäldchen links des von Golencin 
über die Bogdanka führenden Weges gesehen, wäbrend andere, darunter 1 St. sichtbar, sich in der Nähe der Elsenmühle hören liefsen. Es ist nicht daran zu zweifeln, dafs die Vögel hier brüten. Auch in den zur Herrschaft Goray gehörigen, die Uferhöhen des Netzebruches bedeckenden Wäldern (Kreis Czarnikau) ist diese Taubenart nicht selten (H.).

\section{Phasianus colchicus L.}

Verflogene und völlig verwilderte St. dieser Art haben sich im Buschwerk der Wartheinsel und des nahen Steilufers angesiedelt. Am 24. XII. 06 stand, als die angrenzenden militärischen Festungsanlagen abgetrieben wurden, im Schwarzdorngestrüpp des linken Steilufers der Warthe vor einem übergetretenen Jagdhunde ein Fasan auf und warf sich einige $100 \mathrm{~m}$ weiter wieder ins Gebüsch. Am 8. V. 08 konnte man hier das Krähen der Fasanenhähne hören, und am 13. V. flog ein $\bigcirc$ an der Wartheinsel dicht vor unsern Füfsen auf.

\section{Perdix perdix L.}

Im Jahre 1906 konnten wir schon am 21. II. gepaarte Rebhühner beobachten, während dies in den folgenden Jahren erst im Anfang des März der Fall war (2. III. 07; 1. III. 08; 1. III. 09).

\section{Coturnix coturnix L.}

Dieses Hübnchen ist bei Posen schon recht selten. Die Ankunft im Frühjahr fiel-zwischen den 5. Mai und 10. Juni, und zwar wurden im Jahre 19062 Männchen beobachtet (10. VI. aut den Wies en westlich des Viktoriaparks und am 15. VI. an der Südseite des Eichwaldes), 1907: 2 St. an der Südseite des Eichwaldes (10. V. 07 und 20. VI.) und an der Westseite desselben (27. VI.); 1908: wiederum 2 St. (5. VI. 08 auf einem Ackerstück vor der Wolfsmühle und 29. VI. an der rechten Wartheseite gegenüber dem Rennplatze; dies St. rief abends um $1 / 9^{9}$ Uhr recht eifrig). 1909 wurde von uns keine Wachtel gehört.

Auf der Feldmark von Stutendorf wurden nach einer Mitteilung von Professor Heimer 19082 St. geschossen, 1909 ebendort wieder 2 St., wie Professor Selting mitteilte.

\section{Astur palumbarius L.}

Im Jahre 1906 fanden wir im Eichwaldrestaurant in einem Käfig einen jungen Hühnerhabicht vor, der, wie auf Anfrage stud. Nitsche mitteilte, auf der Eichwaldstrafse gefunden worden war. Der Vogel wurde dem hiesigen zoologischen Garten aberwiesen. 


\section{Accipiter nisus L.}

Sperber zeigten sich zwar das ganze Jahr hindurch, jedoch immer ziemlich selten, am häufigsten noch zur Zugzeit im Frühjahr und im Herbst. Am 18. III. 08 flog ein Sperberweibchen, vom Eichwalde herkommend, über die Wiesen westlich des Viktoriaparks hinweg und brachte einen Kiebitzschwarm in nicht geringe Aufregung (vgl. oben S. 395). Am 19. III. 08 kam ein Schwarm Haussperlinge von der Umschlagstelle ber und nahm die Richtung nach dem Schlachthofe, machte aber in der Nähe des Hauses, in dem sich das Restaurant zur Börse befindet, blitzschnell kehrt und verschwand wie auf Kommando in den offenen Bodenluken. In demselben Augenblicke erschien ein Sperberweibchen von dem gegenüberliegenden Holzplatze und hatte das Nachsehen. Es machte unmittelbar an den Luken eine Wendung nach oben und verschwand, über das Dach hinwegstreichend.

Auffällig hänfig war der Sperber im Herbst des Jahres 1907 auf der Feldmark von Stutendorf, wo es freilich von Kleinvögeln wimmelte. Am 29. IX. wurde hier wohl ein halbes Dutzend beobachtet, wohl meist junge Vögel, die ihr Räuberbandwerk noch nicht recht verstanden. So entkam über einem Kartoffelfelde ein Vogel, anscheinend ein Grünling, glücklich den ungeschickten Stölsen eines kleinen Räubers, und über einem andern Kartoffelstücke wurde $1 \mathrm{St}$. erlegt, das sich als junges $\sigma^{7}$ erwies. Auch in unserm eigentlichen Beobachtungsgebiete wurden besonders im Herbst Spuren der Mahlzeiten des Sperbers gefunden und zwar an ganz verschiedenen Örtlichkeiten, so am 14. X. 09 an der Nordseite des Rennplatzes (vermutlich von einem Grauammer) und am 18. $X$. in der Nähe des Wartheknies unterhalb der Wolfsmühle (von einer Lerche). An demselben Tage flog 1 St. an der Wartheinsel über uns hinweg.

Im Winter brandschatzte der Sperber nicht selten mit grofser Dreistigkeit die Spatzenherden mitten in der Stadt. So holte sich 1 St. mehrere Tage hintereinander seine Beute aus dem Garten des Restaurant Beely.

Am 5. XII. 08 erschien um $3 / 410$ a ein Sperberweibchen in der Nähe der Fronleichnamskirche. Ein Schwarm Goldammern, die friedlich auf einer Kastanie safsen, schols plötzlich hoch in die Luft empor und wufste sich sehr geschickt stets hoch über dem Erbfeind zu balten. Der Raubvogel zog denn auch, obne zu stofsen, nach der Warthe zu ab.

Am 17. I. 09 kam gegen $1 / 212$ Uhr mittags ein Sperberweibchen von der Halbdorfstrafse her auf den Petrikirchhof und bäumte, von 2 Krähen belästigt, in der Nähe eines Futterkastens auf einer hohen Linde auf. Wie es schien, interessierte den Raubrogel das Rufen einer Blaumeise; er flog jedoch, als er Menschen in seiner Nähe gewahrte, in der Richtung auf die Ritterstrafse $\mathrm{zu} a b$. 


\section{Buteo buteo L.}

Den Mäusebussard bekommen wir hier nur selten zu Gesicht, am meisten noch im Frühjahr und im Herbst, besonders in unserm Eichwalde. Am 30. IX. 09 flog 1 St. um 5 Uhr p in westlicher Richtung über den Eichwald hinweg; am 14. X. wieder 1 St. im Eichwalde, niedrig über den Bäumen hinziehend.

\section{Archibuteo lagopus Brünn.}

Am 16. IV. 08 wurde aus Chwalibogowo bei Wreschen ein vom stud. v. Skrbenski erlegtes St. dieser Art eingesandt, ein zweites am 21. IV. 08 vom Gutsbesitzer Walther aus Ruschkowo bei Schroda, das aus einer Schar von 6 St. erbeutet worden war. Beide Vögel stehen in der Sammlung der hiesigen Berger-Oberrealschule.

\section{Falco subbuteo L.}

Am 5. IX. 05 wurde ein St. dieser Art vom stud. Nitsche eingesandt, dafs im Eichwalde erlegt worden war. Der Vogel steht in der Sammlung der hiesigen Berger-Oberrealschule.

Am 30. IV. 09 zog um 63/4 p ein Paar dieser Vögel jagend zwischen Schilling und Kernwerksanlagen vorbei. Ein starker Schwarm Schwalben (Mehrzahl Stachelschwalben, unter die sich einige Mehl- und Erdschwalben gemischt batten), der eben noch über der Warthe dem Insektenfang obgelegen hatte, erhob sich eiligst hoch in die Luft, die Falken übersteigend und ihnen ausweichend. Die Schwalben wurden von den Raubvögeln völlig ignoriert. Am 19. V. 09 strich nachmittags ein Baumfalk über den nördlichen Teil des Eichwaldes zwischen dem Försteracker und Eisenbahndamm hinweg. Um das Jahr 1897 war der Baumfalk Brutrogel in einem kleinen Kiefernwäldchen bei Czerwonak Ein Junger ad. wurde hier auf der Feldmark erlegt.

\section{Cerchneis merilla (Gerini).}

Der Merlinfalk erscheint ab und zu bei uns als Wintergast. Am 24. XII. 06 jagte 1 St. an der Wartheinsel, wurde jedoch in seinem Geschäft von einer Mantelkrähe gestört, nach der es jedesmal bifs, wenn sie nach ihm stiels. Auch bei einer andern Gelegenheit hinderte eine Krähe diesen kleinen Falken in der Betätigung seines Räuberhandwerks. Am 3. II. $08 \mathrm{kam} \mathrm{um} 21 / \mathrm{p}$ ein Merlin von links her an der Stelle des ehemaligen Wildatores vorbei und flog dem gegenüberliegenden Kirchhofe zu, wo er aufbäumte. Nach kurzer Zeit flog der Vogel wieder ab und zog quer an uns vorüber nach dem Grundstücke der Hugger-Brauerei, wo er auf wenige Augenblicke verschwand, um bald wieder, einen Sperling in den Fängen tragend, aufzutaucben. Da machte plötzlich eine Krähe einen heftigen Angriff auf ihn. Der erschreckte Vogel 
liefs die Beute fahren und zog eiligst von dannen. Leider konnte nicht festgestellt werden, wie dem Meister Spatz dieses Abenteuer bekommen war.

Am 11. II. beobachteten wir gegen 3 Uhr $p$ einen Merlin rech ts der Eichwaldstrafse, der in dem ihm eigentümlichen Fluge niedrig über die Wiesen hinstrich und sich niederliefs, aber weiterzog, als wir uns ihm bis auf etwa 50 Schritt genähert hatten. Es handelte sich vermutlich um dasselbe Stück wie vorher.

\section{Cerchneis tinnuncula L.}

Am 4. II. 06 liefs 1 St. über den hohen Kiefern der Nordseite des Eichwa!d es (seinem gewohnten Brutplatze) seinen Paarungsruf (kli kli - . - ) hören. Das St. dürfte hier überwintert haben, was sonst selten der Fall ist. In der Regel erschienen die Turmfalken bei uns im März: 4. III. 07 im Eichwalde rufend; 18. III. 08. ebendort rufend; 14 . III. 09 an der Warthe gegenüber dem Viktoriapark auf einer niedrigen Erle sitzend und auf Beute lauernd. Als wir ziemlich nahe herangekommen waren, flog der Vogel, augenscheinlich aufgebracht, der Stelle zu, wo die Maus erscheinen sollte, wendete sich dann aber seitwärts, wo er etwa 20 Schritte weiter zu rütteln begann, sich niederliefs und mit einer Maus in den Fängen dem Viktoriapark zustrich. Goldammern liefsen sich durch den Vogel nicht im geringsten in ihrem Gesange stören.

Im Jahre 1909 nisteten 3 oder 4 Paare dieser Vögel im Eichwalde und zwar auf den mächtigen Kiefern im nördlichen und südlichen Teile. Im März und April liefsen sie eifrig ihren Paarungsruf hören, wobei sie meist $30-40 \mathrm{~m}$ hoch über den Bäumen hin und her strichen. Im Mai und später hörte man häufig in der Nähe des Horstes ein eigentümliches Zirpen, wie tirrr klingend, und ein in kleinen Abständen wiederholtes tik.

Sind die Jungen völlig erwachsen, so zerstreuen sie sich in der Umgegend, so dafs man dann Turmfalken auch an Stellen beobachten kann, wo sie sich in der Brutzeit nicht aufhalten. So sals am 6. IX. 09 ein junger Vogel ad. auf einer Weide an der Ostseite der milit. Schielsstände vor dem Warschauer Tor. Aufgescheucht, strich der Vogel über die Cybinawiesen hin nach den Erlen bei Johannistal. Am 13. IX. war der Vogel wieder in den Anlagen der Schiefsstände. Er bäumte auf der trockenen Spitze einer hohen Pappel auf, ohne dafs das Kleingevögel (Grünlinge, Buchfinken) die geringste Furcht zeigte, ja einige Finken, die sich in immer gröfserer Zahl auf den trocknen Zweigen der Pappel ansammelten versuchten sogar den Falken zu necken, indem sie nach ihm stiefsen. Schliefslich flog er aufs freie Feld, wo er rüttelnd der Mäusejagd oblag. Auch am 26. IX. wurde noch 1 St. auf den Schiefsständen gesehen, das auch mehrmals rief.

Wir haben bisher nie einen Turmfalken auf kleine Vögel stofsen sehen, wohl aber wurde er selbst bisweilen von diesen 
wie auch von Krähen belästigt. Am 15. IX. wurde $1 \mathrm{St}$, das an der Wartheinsel vorbei dem am rechten Wartheufer unterhalb der Militärfähre liegenden Kiefernwäldchen zustrich, von einer Krähe verfolgt und geneckt und am 18. X. 1 St. in derselben Gegend von einem Stieglitzpärchen belästigt. Wiesenpieper, die sich in der Nähe herumtrieben, zeigten sich in keiner Weise beunruhigt.

\section{Asio otus L.}

Die Waldohreule hat in den Jahren 1906-09 (nur 1908 nicht beobachtet) regelmäfsig in unserm Eichwalde gebrütet und zwar in dem meist aus mächtigen Kiefern bestehenden nördlichen Teile desselben. Wenn auch das Nest nicht entdeckt wurde, so lälst doch die Beobachtung der Jungen keinen Zweifel aufkommen. Am 15. VI. 06 machte sich eine junge Ohreule in der Nähe der Grenzlache am Nordrande durch einen quarrenden Ton bemerkbar, dem bald ein dem Fiepen eines Rebkitzes ähnlicher Laut folgte; nicht weit davon bettelte ein zweites St. Abends gegen 9 Uhr safsen beide Jungen 3 bis $4 \mathrm{~m}$ hoch dicht neben einander auf einem $Z$ weige und fiepten um die Wette. Der Laut klang in der Nähe wie ein gedehntes, etwas herabgezogenes ihrp. Aufgescheucht, flogen sie etwas weiter, wobei 1 Junges mehrmals ein unwilliges quuog rief, worauf sich das gedämpfte wumb oder wupp eines Alten aus dem dichten Gezweige einer Kiefer hören liefs. Von hier flog denn auch der Vogel ab.

An demselben Tage des folgenden Jahres (15. VI. 07) hörten wir wieder das Fiepen der Jungen. Am 22. VI. machte uns das Gezeter der Grasmücken auf 1 Junges aufmerksam, das hoch aufgerichtet an einer sonnigen Stelle auf einem niedrigen Baume sals und einige Schritte weiterflog, als wir uns ihm bis auf etwa 8 Schritte näherten. Am 25. VI. Hlog eine junge Eule dicht über unsern Köpfen ab. Am 1. VII. war um $1 / 29$ p das Fiepen der Jungen wieder zu hören.

Am 20. III. 08 sals an einer kleinen Lichtung an der Westseite des Eichwaldes etwa $11 / 2 \mathrm{~m}$ hoch eine Ohreule, die zwar leise knurrend und schnabelklappend ihrem Unwillen über die Störung Ausdruck gab, aber nicht abflog, als wir auf etwa 30 Schritt an ihr vorbeigingen. Junge wurden in diesem Jahre nicht beobachtet, wohl aber war wieder im Jabre 1909 wiederholt der fiepende Ruf zu hören (am 24. VIII., ebenso am 27. und 28. VIII.) und zwar um 6 Uhr abends.

\section{Syrnium aluco L.}

Der Waldkauz wurde hier fast jedes Jahr beobachtet, ohne dals es uns bisher gelungen wäre, sein Brüten mit Sicherheit festzustellen; doch liefs er am 27. V. 07 um 9 Uhr $p$ in den Anlagen des Kernwerks unfern des Pulverhauses Balzrufe hören. In diesen Anlagen wurden Waldbäuze des öfteren beobachtet, 
und auch an andern geeigneten Plätzen fehlten sie nicht. Am 12. V. 02 trafen wir im Kernwerk auf 1 St. (braune Färbung), das von einigen Buchfinken umlärmt wurde. Am 16. V. 06 flog um 7 Uhr $p 1$ St. an der Wartheinsel vorbei nach den benachbarten Festungsanlagen, von einer Elster und einigen kJeinen Vögeln verfolgt; am 23. V. machte der Vogel die umgekehrte Tour von den Festungsanlagen nach dem am andern Flufsufer liegenden Kiefernwäldchen.

Am 4. VIII. 07 flog 1 St. von den Kiefern auf der Südseite des Eichwaldes ab, auf das uns der Warnruf eines Gartensängers und das Zickern eines Rotkehlchens aufmerksam gemacht hatten. Auch im folgenden Jahre (26. VI. 08) trafen wir einen Kauz (braune Färbung) in dem Kiefernstangenholz an der Südwestecke des Eichwaldes. Das ängstliche derboi eines Hippolais veranlafste uns, nach der Ursache zu forschen, worauf der Waldkauz abflog. Der Gartensänger sang wie triumphierend einige Strophen und war dann still. Dafür aber erhoben aus der Richtung, die die Eule genommen, andere kleine Vögel ihre warnenden Stimmen, und es gab ein artiges Gezeter, als Buchfink, Gartensänger, Fitis und andere ihre Stimmen mischten. Der Kauz flog bei unsrer Annäherung weiter, wurde aber auch jetzt wieder vom Lärm der Kleinvögel empfangen.

Am 27. IV. 09 war gegen $7 \mathrm{Uhr} p$ I St. von der braunen Form in den Anlagen des Kernwerks (Schillingseite) sichtbar, und am 29. VI. flog 1 St. an der Südseite der Wartheinsel aus dem niedrigen Buschwerk im alten Warthebett auf und wendete sich den Festungsanlagen zu (graue Färbung).

\section{Sumia ulula L.}

Am 12. XI. 05 wurde ein vom Förster in Unterberg, Forstbaus Seeberg, geschossenes Stück dieser hier offenbar als Wintergast erscheinenden Art eingeliefert. Es steht in der Sammlung der hiesigen Berger-Oberrealschule.

\section{Athene noctua Retz.}

Am 14. IX. 07 rief um $3 / 49 \mathrm{Uhr} p$ auf einer Pappel hinter der Scheune der Pfarrei Ketsch ein Steinkauz sehr lebhaft sein gellendes kuit.

\section{Cuculus canorus $\mathrm{L}$.}

Ankunftszeiten: 2. V. 03; 17. IV. 04 (an der Cybina zwischen Schlofspark Ostend und Ringstrafse kreuzte ein Kuckuck unsern Weg, doch nicht rufend); 24. IV. 04 (rufend auf den Pappeln der Eichwaldstralse; dann unter lebhaftem Geschrei von Bachstelzen verfolgt, flüchtet er ins Glacis am Wildator); 30. IV. 05; 27. IV. 06; 5. V. 07 (rufend; endlich Frühlingswetter, Südwind); 25. IV. 08 (rufend im Eichwalde); 1. V. 09 (rufend im Kobyle- 
poler Grunde). Ein an seiner heiseren Stimme gut kenotlicher Kuckuck, der in der Nähe der Wartheinsel seinen Standort hatte, rief zum ersten Male am 17. V. 08 und 13. V. 09, kam also erheblich später an als einige seiner Artgenossen. Noch am 2. VII. 08 rief ein $\sigma^{x}$ eifrig im Eichwalde, und auch das $\subsetneq$ liefs zweimal seinen kichernden Ruf hören.

Der Abzug ist schwer zu beobachten; meist erfolgte er wohl am Anfang des August, doch war ausnahmsweise noch am 22. VIII. 091 St. einen Moment an der Südseite des Eichwaldes sichtbar.

Am 21. V. 09 beobachteten wir um $3 / 47 \mathrm{p}$ einen weiblichen Kuckuck, der auf den Cybinawiesen oberhalb des Schlofsparks Ostend unruhig hin- und herflog, bald dicht über dem Grase hinstrich, bald sich ins Gras niederliefs und hier hüpfend umbersuchte. Wir sahen dem Treiben des Vogels $\mathrm{zu}$, verloren ihn dann aber mehrere Minuten an einer etwas höher begrasten Stelle aus den Augen. Dann flog er wieder auf, strich hin und her, setzte sich auf seitwärts an einem Grabenrande stehende Erlenbüsche, schlug dann mehrmals die Richtung nach dem Wege ein, auf dem wir standen, und bäumte auf den Wegweiden auf, um dann wieder auf die Wiesen jenseits des Flüfschens zurückzukehren. Er zeigte sich am Wege so wenig scheu, dals er sich bis auf 20 Schritt angehen liefs. Um 1/28 Uhr tlog er in der uns entgegengesetzten Richtung ab und setzte sich einige $100 \mathrm{~m}$ weiter auf eine Weide bei Johannistal. War der Vogel etwa auf der Nestersuche? War das der Fall, so dürfte auf diesem Gelände wohl nur Anthus pratensis oder Pratincola rubetra in Frage kommen. Der Vogel liefs bei seinem geheimnisvollen Tun keinen Laut hören und schien uns gegenüber grofses Milstrauen an den Tag zu legen.

\section{Jyna torquilla L.}

Ankunftszeiten: 24. IV. 03 (sichtbar); 23. IV. 04 (im Eichwalde rufend); 29. IV. 05; 18. IV. 06 (schöner April, die Bäume teils belaubt, teils blühend); 29. IV. 07 (rufend im Kernwerk, im Schilling 3 St. einander jagend); 24. IV. 08 (im Schilling rufend); 19. IV. 09 (ebendort rufend).

Die Brutzeit fällt in den Mai. Am 3. V. 08 arbeitete 1 St. an einem Astloche auf dem Petrikirchhof, dabei sich öfter unterbrechend und rufend (12 Uhr mittags). Im Juni war der Ruf der Alten schon selten zu bören, doch wurde er noch am 15. VI. 07 im Eichwalde vernommen, ebendort am 24. VI. noch an 2 Stellen, am 7. VI. 09 noch im Schilling.

Meist erst im Juli (1905 im Kernwerk) hört man das charakteristische Schwirren der ausgeflogenen Wendehälse, das recht sehr an das Schwirren von Loc. fluviatilis erinnert. Es klingt etwa wie sitte sitte -.. - oder sise - ... Im Jahre 1907 ertönte dieses Schwirren schon am 26. VI. im Kernwerk, und die Urheber wurden 
mittels Fernglas festgestellt. Am 3. VIII. 09 schwirrte noch ein Junges jedenfalls aus einer Spät- oder Ersatzbrut stammend, im Eichwalde. In der zweiten Hälfte des August haben wir hier keinen Wendehals mebr gesehen. Als spätester Termin wurde der 5. VIII (1909) notiert, wo ein St. hinter den militärischen Schiefsständen vor dem Warschauer Tor verweilte.

Am 29. IV. 07 wurde ein Wendehals im Vorgarten des Mariengymnasiums beobachtet, der auf dem gepflasterten Eingange eifrig Futter aufnahm. Bei der Besichtigung der Stelle zeigte sich, dafs der Vogel eine Ansiedelung einer kleinen gelben Ameise fast gänzlich aufgerieben hatte.

\section{Dendrocopus maior L.}

Unter den Spechten ist diese Art bei Posen entschieden am bäufigsten. Man findet sie in jeder nicht zu kleinen Waldparzelle, und auch in unsern Festungsanlagen fehlt sie nicht: im Solatscher Wäldchen, im Kobylepoler Grunde, im Eichwalde, in den Anlagen des Kernwerks und auch im Schilling, wo man im Frühjahr manchmal das Trommeln dieser Spechtart beobachten kann. Im Herbste streichen die Vögel umher, und so konnte man sie auch in der Wolfsmühle sehen und hören (18. X. 09). Am 17. X. beobachteten wir im Eichwalde 4 St.

Am 20. IX. 09 machte sich an der Wartheseite des Kernwerks ein o eifrig klopfend an einer Weide zu schaffen. Bei unsrer Annäherung rutschte der Vogel wie üblich auf die andere Seite des Stammes, wurde hier aber von einem Buchfinkenmännchen angegriffen und räumte, obne sich zu verteidigen, das Feld.

\section{Dendrocopus minor L.}

Ein anrnutiges Balzspiel zweier Kleinspechte, wie es von Dr. Hesse im J. f. 0. 1909 I p. 19 beschrieben wird, beobachteten wir am 21. III. 04. Die Tierchen machten sich an den mächtigen Pappeln zu schaffen, die an der Stelle stehen, wo der Fahrweg nach dem Schilling von der Stralse abbiegt. Ein St. folgte dem andern in einer eigentümlichen Art schwebenden Fluges. Als sie den dicken Stamm einer Schwarzpappel erreichten, saísen sie eine Weile, etwa 11/, $\mathrm{m}$ über dem Erdboden, völlig regungslos mit etwas abgespreizten Flügeln, wobei $1 \mathrm{St}$. ein leises $\mathrm{ki} \mathrm{ki} \mathrm{-.}$ hören liefs. Das gleiche Spiel wiederholte sich bald darauf an einer zweiten Pappel. Die Vögel zeigten so wenig Scheu, dals sie sich bis auf 5 Schritt angehen liefsen.

Der Kleinspecht ist in der Umgegend Posens nicht selten, wenn auch nicht so häufig wie sein grö́serer Vetter. Er macht sich fast das ganze Jahr hindurch durch sein frisches ki ki - - bemerklich. So rief er am 20. II. 09 an der Wartheseite des Kernwerkes (Schneedecke), am 17. VIII. im Schilling, am 21. VIII. im Eichwalde, am 2. IX. auf dem Kirchhofe zwischen Wilda- und 
Rittertor, am 14. IX. im Schilling, am eifrigsten natürlich während der eigentlichen Brutzeit, in der er sich auch $a b$ und zu durch Trommeln bemerkbar machte.

Am 8. IX. 08 zog er im Eichwalde mit einem Meisenschwarm umher, wie man das häufiger bei der vorigen Art beobachten kann.

\section{Picus viridis L.}

Wie der Kleinspecht, so liefs auch der Grünspecht oft schon im Februar seinen klangvollen Paarungsruf hören, wodurch er die Gegend um den Schilling, in dem er mehrmals in einer alten Weide $10-15 \mathrm{~m}$ hoch nistete, aufs anmutigste belebte, so am 21. II. und 23. II. 06. Nur im Frühjabr 1907 war hier kein Vogel zu sehen und zu hören. Ob der strenge Winter den Vögeln verhängnisvoll gewesen war? Erst am. 26. IV. hörten wir in diesem Jahre einen Grünspecht im Eichwalde, während er im Jahre 1908 sich wieder früher, nämlich am 7. III. an der Scheibenseite der milit. Schiefsstände vor dem Warschauer Tor hören liefs. Hier hing ein St. an einer Pappel unterbalb des Wipfels und rief von Zeit zu Zeit, worauf ein $\mathrm{zweites}$ St. vom Spechtschen Schiefsstande her prompt antwortete. 1909 rief 1 St. schon am 13. II. um $1 / 24 \mathrm{p}$ im Schilling, trotzdem es empfindlich kalt war (nachts $-16^{\circ}$, tagsüber $-6^{0}$ ) und eine Schneedecke die Erde einhüllte.

Im Spätsommer und im Herbste riefen die Grünspechte seltener, und der Ruf klang meist abgebrochener, härter. Häufig wurde beobachtet, dafs der Grünspecht, ehe er im Spätjahr seine Schlafstätte aufsuchte, ein mehrmaliges hartes klück (oder kjück) ausstiefs, nachdem er sich in der Nähe derselben, meist auf einem benachbarten Baume angehakt hatte, so im Kernwerk, wo 1 St. im Astloch einer Birke übernachtete, oftmals, ferner auf den Schiefsständen vor dem Warschauer Tor (am 22 . IX. 09 um $1 / 26 \mathrm{p}$, in den Festungsanlagen an der Wartheinsel (am 13. X. und 18. $X$. um 1/6 p), an der Wartheseite des Kernwerks (am. 29. VIII. 08 um $61 / 4 \mathrm{p}$ und am 4. XII. 08). Vielleicht bezog an letztgenannter Stelle der Vogel wieder eins der zablreichen Löcher in der Festungsmauer als Schlafplatz, wie wir das im Jahre 1906 bei einem Exemplar beobachtet batten. Der Vogel flog abends eine Pappel in der Nähe des Wallgrabens an, rief mehrmals sein klück und flog dann, während wir unter dem Baume standen, zu einem Mauerloch, in dem er verschwand.

Am 30. IV. 04 saben wir dem Balzspiele zweier Grünspechte im Eichwalde zu. Die Vögel trieben sich dabei an einigen Birkenstämmen in unmittelbarer Nähe des Erdbodens unter mancherlei Balzgebärden umher, einander mit leiser Stimme zurufend.

Junge Grünspechte wurden im Schilling mehrfach beobachtet, zuletzt im Jahre 1909, indem ein heilshungriges St. den Kopf immer wieder verlangend aus dem Brutloche herausstreckte, während ein paar Geschwister bereits ausgeflogen waren. 


\section{Picus canus viridicanus Wolf.}

Rufe des Grauspechts hörten wir am 10. VI. 09 im Buchenwalde von Boguniewo, Oberförsterei Eckstelle.

\section{Alcedo ispida L.}

Bis zum Jahre 1907 wurden Eisvögel mehrfach beobachtet, selbst mit erwachsenen Jungen (an der Einmündung der Cybina in die Warthe), einzelne Stücke regelmälsig an gewissen Lachen im Eichwalde; in der Folgezeit aber war der Vogel hier entschieden seltner und konnte nur noch in wenigen Fällen mit Sicherheit nachgewiesen werden. Am 2. V. 08 umkreiste uns unterhalb der Wolfsmühle in der Nähe einer Lache unter ängstlichen Rufen (tiht) ein Vogel dieser Art. Er setzte sich mehrmals auf dio unteren Zweige kleiner Pappeln, flog nach einigen Augenblicken ab und warf sich an einer Seite der Lache, wo diese etwas höhere Ufer hat, zur Erde nieder. Wir mulsten den Eindruck gewinnen, dafs wir uns im Brutgebiete des Vogels befanden, konnten jedoch die Brutröhre trotz eifrigen Suchens nicht finden. Später wurde der Vogel hier nicht wieder gesehen. Im folgenden Jahre, am 2. IX. 09 wurde ein St. in derselben Gegend bemerkt, und am 18. X. verriet sich uns $1 \mathrm{St}$. beim Absuchen der einzelnen Tümpel der faulen Warthe durch sein tiht, das bei unserer Annäherung von einem über das Wasser hinausragenden Weidenzweige abstrich.

\section{Coracias garrulus L.}

Die auffallende Blauracke wurde vor mehreren Jahren wiederholt in der Näbe von Czerwonak und Owinsk beobachtet und einmal vom Eisenbahnzuge aus bei Jankendorf, unfern von Rogasen, gesehen. Auch bei Schönlanke wurde der Vogel mehrfach beobachtet (S.).

\section{Upupa epops $\mathrm{L}$.}

Der Wiedehopf traf hier in der zweiten Hälfte des April oder Anfang Mai ein und zwar: am 7. V. 03; 16. IV. 04 (an der Wartheseite des Eichwaldes); 26. IV. 05; 30. IV. 06; 1. V. 07 (Wartheseite des Schillings); 25. IV. 08 (im Eichwalde); 6. V. 09 (im Eichwalde, im Fluge järp oder schräp rufend).

Wiedehopfe waren hier nicht selten. Der Vogel war im Eichwalde regelmälsig, auch paarweise, vorbanden (6. V. 07), von wo er Ausflüge auf die nahen Viehweiden unternahm (13. V. 08). Es ist nicht $z \mathfrak{u}$ bezweifeln, dafs der Vogel hier, wo die alten durch die Frübjahrsüberschwemmungen stark mitgenommenen Eichen Brutlöcher im Fülle bieten, nistet. Aufserdem wurde der Vogel alle Jahre beobachtet an dem Wege, der von Golencin aus über die Bogdanka führt, so am 1. V. 04 und am 9. VI. 09; hier bieten kernfaule Weiden und Pappeln Gelegenheit zum Brüten. Auch hinter den Scheibenständen vor dem Warschauer 
Tor trieb sich am 25. VI. 08 ein Pärchen umher, das sich zeitweilig neckte und jagte, und auch am 11. V. 09 war hier 1 St. sichtbar. An allen diesen Stellen machten sich die Vögel durch lebhaftes Rufen bald bemerkbar.

Der Abzug scheint in der ersten Uälfte des August zu erfolgen. Am 2. VIII. 08 flogen $2 \mathrm{St}$., ihr schräp rufend, über den Eichwald hinweg. Am 8. VIII. war hier noch 1 St. sichtbar. Am 3. VIII. 09 trieb sich 1 St. im der Nähe des Ausschachtungstiimpels vor dem Eichwalde umher und am 5. VIII. 1 St. hinter den Schiefsständen vor dem Warschauer Tor. Am 10. VIII. noch 1 St. sichbar, nach diesem Termine keins mehr.

\section{Caprimulgus europaeus L.}

Als wir uns am 30. IV. 09. gegen $7 \mathrm{Uhr} p$ vom Schilling aus dem Schillingstore zuwandten, bemerkten wir in der Nähe des durch die Kernwerksanlagen führenden Fufssteiges einen Vogel dieser Art, der auf einem etwa $3^{1 / 2} \mathrm{~m}$ über der Erde wagerecht ausgestreckten, armdicken Zweige einer Robinie in dessen Längsricbtung bewegungslos safs. Obwohl wir unter den Ast traten und den Vogel eine Zeitlang beobachteten, flog dieser nicht ab. Er sah einem alten Zanken täuschend ähnlich, der Kopf, mit dem übrigen Leibe eine wagerechte Linie blidend, lag nicht auf dem Zweige auf, sondern liefs einen kleinen Zwischenraum frei. Der Vogel hat offenbar hier auf dem Frühjabrszuge gerastet und ist dann weitergezogen, denn in der Umgebung Posens ist dieser Vogel sonst nicht zu finden, wohl aber ist er nicht selten in andern Teilen der Provinz, z. B. bei Bromberg und bei Kolmar i. P.

\section{Apus apus L.}

Ankunftszeiten: 4. V. 02; 3. V. 03; 7. V. 04; 1. V. 05; 5. V. 06; 5. V. $07 ; 30$. IV. 08 (2 St. unter zahlreichen Stachelschwalben in der Näbe der Warthe oberhalb der Badeanstalt von Döring); 27. IV. 09 (um $3 / 410$ a schwebten einige St. über dem FriedrichWilhelms-Gymnasium; Wetter sehr warm mit südwestlichem Winde; auch am folgende Tage mehrere sichtbar, während die Hauptmasse wie gewöhnlich erst im Mai eintrat.

Der Mauersegler ist gemeiner Brutvogel in der Stadt Posen. Er nistet hier hauptsächlich in Löchern unter den Dächern der Häuser. Abends dehnt er seine Jagd länger aus als irgend ein anderer Vogel; erst mit Eintritt der Dunkelheit werden die Schlafstätten aufgesucht.

Der Abzug erfolgt in der Regel gegen Ende Juli oder im Anfange des August. Am 3. VIII. 07 liefsen sich nur noch wenige Vögel sehen und hören, die vermutlich einer verspäteten Brut angehörten. Am folgenden Tage waren auch sie verschwunden.

$\mathrm{Am}$ 2. VIII. 08 waren alle Mauersegler abgezogen. Der Umschlag der Witterung am 1. VIII,, der mit Regen und West- 
winden Abkühlung brachte, hatte sie von hinnen getrieben; doch wurde ain 15. VIII. noch ein einzelnes St. über den Überschwemmungslachen vor dem Wartheknie beobachtet.

Am 3. VIII. 09 lagen noch zahlreiche Vögel hoch in der Luft über dem ehemaligen Eichwaldtore dem Insektenfange $o b$, ebenso um $71 / 4$ p ein Schwarm von mindestens 50 St. über dem grünen Platze, unter ibnen auch Dorf- und Stadtschwalben. Am 4. VIII. jagte gegen 8 Uhr p ein Schwarm von einigen 20 St., dicht gedrängt fliegend und laut schreiend, über dem Bahnhof Gerberdamm hin und her und verschwand dann anscheinend in westlicher Richtung, wo der Himmel, sonst bedeckt, klar war; das Wetter war gewitterschwül. Ein zweiter Schwarn tummeite sich schreiend hoch in der Luft über dem Kernwerk. Nur zwei einzelne Vögel flogen niedrig über dem Güterschuppen des Bahnhofs Gerberdamm, während in der Stadt kein Segler mehr sichtbar war. Am 5. VIII. noch zahlreiche Vögel über den Häusern bis 10 Minuten vor $8 \mathrm{Uhr} p$ (abends $8 \mathrm{Uhr}+2^{\circ} \mathrm{C}$.). $\mathrm{Am}$ 6. VIII. waren die meisten verschwunden, nur über dem Schlachthofe flog noch ein Schwarm von $10-15$ St. umher und einige wenige über dem Rathausturm. Am 7. VIII. waren nur noch einige Durch- und Nachzügler zu sehen; Witterung sehr warm. Am 8. VIII. und an den folgenden Tagen war, trotzdem die warme Witterung anhielt, kein Segler mehr sichtbar. Erst am 3. IX. zeigten sich wieder um $1 / 26 \mathrm{p} 2$ Nachzügler unterhalb des Schillings inmitten von Dorf- und Stadtschwalben.

\section{Himendo rustica L.}

Die Rauchschwalbe zeigte sich in einzelnen Exemplaren in der Regel um die Mitte des April. Ankunftszeiten: 9. IV. 04 (an der Warthe vor dem Eichwalde); 20. IV. 05; 12. IV. 06 (1 St.); 15. IV. 07 (gegen Abend 1 St. in der Halbdorfstrafse hin und her schiefsend und zweimal in dem Fenster einer Bodenkammer verschwindend); 16. IV. 08; 16. IV. 09 (1 St. über der Warthe unterhalb des Schillings; am 17., einem schönen Frühlingstage, tummelten sich zahlreiche Schwalben über den überschwemmten Wiesen zwischen Schilling und Gluwno. Die Vögel waren jedenfalls mit Südwestwind in der vorhergehenden Nacht eingetroffen.).

Am 30. IV. 09. jagte ein Schwarm von 50-80 St., darunter einige Mehl- und Uferschwalben, unter Wind über der Warthe unterhalb des Schillings. Um $3 / 47 \mathrm{p}$ stieg plötzlich die ganze Masse eiligen Fluges und ohne Laut hoch in die Luft, einem daherziehenden Baumfalkenpaare ausweichend.

Am 22. VI. 07 hatten in einem zum Forsthause im Eichwalde gehörigen Stalle die Jungen der ersten Brut das Nest verlassen und safsen nachmittags, 6 an Zahl, neben einander auf dem Zweige eines Baumes. 
Am 19. V. 09 war ein Schwalbenpaar unter der Veranda des Eichwaldrestaurants beim Nestbau. Am 21. VI. wurden daselbst Junge gefüttert; ausnahmsweise nahm eine Alte trippelnd von der Erde Futter auf und trug es den Jungen zu. Am 28. VI. wurden Anstalten zur 2 weiten Brut gemacht, das $\sigma^{7}$ sang eifrig. Am 3. VIII. wurden die Jungen der zweiten Brut gefüttert (im vergangenen Jahre ging die zweite Brut infolge Ungunst der Witterung zugrunde); am 18. VIIL. flogen die Jungen aus, kehrten aber nachts ins Nest zurück. Am 24. VIII. wurden die Jungen noch in der Nähe der Brutstelle gefüttert.

Am 2. VII. 08 hatten sich zahlreiche erwachsene Junge der ersten Brut zusammengeschlagen. Sie sammelten sich gegen Abend, eifrig 2 witschernd, über der Warthe östlich des Rennplatzes, um in einem Rohrtümpel am gegenüberliegenden Wartheufer zu nächtigen. Am 3. IX. 09 suchte um 1/4 7 ein Trupp Rauchschwalben seinen Schlafplatz im Röhricht eines Tümpels in der Nähe der Wartheinsel auf. Die Vögel näberten sich der Stelle, hoch in der Luft eifrig zwitschernd und hin und her jagend. Gegen $3 / 47 \mathrm{Uhr}$, als es dunkelte, senkten sie sich, zogen im Weidicht mehrmals auf und ab und schossen dann lautlos dem Röhricht zu. Am 15. IX. sammelten sie sich gegen $6 \mathrm{Ohr}$ in der Nähe des Rohrtümpels.

Der Abzug der Rauchschwalben erfolgte meist Ende September bis Mitte Oktober, nur ausnabmsweise wurden noch über diesen Termin hinaus Schwalben beobachtet. So wurden am 16. X. 05 noch einige St. in der Villenstrafse in Unterwilda gesehen. Dann waren die Vögel anscheinend alle verschwunden. Da erschienen auffallenderweise wieder gegen den Ausggang dieses Monats zahlreiche Rauchschwalben, die augenscheinlich schwer unter der Ungunst der Witterung zu leiden hatten, da bereits regelmärsig Nachtfröste eintraten. Die Tierchen suchten mehrfach Schutz in den Korridoren des Mariengymnasiums. Hier wurde ein völlig ermattetes, halbverhungertes St. vom Oberlehrer Brock gefangen. Der Vogel, der sehr abgemagert war, nahm das dargebotene Futter gierig an, starb aber am andern Tage, da der geschwächte Magen wohl nicht mehr imstande war, die aufgenommene Nabrung gehörig zu verarbeiten. Erst gegen den Anfang November verschwanden die Schwalben bei Eintritt milderer Witterung.

Im Jahre 1909 zog die Hauptmasse der Rauchschwalben ziemlich früh trotz der warmen Witterung (der 17. und 18. September brachten starke Gewitter ohne Abkühlung) aus der Umgegend Posens fort. Am 19. IX. wurden noch 6 St. nachmittags über dem Rohrtümpel vor der Wartheinsel gezählt; noch um $6^{10}$ flog 1 St. hier niedrig hin und her. Am 20. IX. war keine mehr sichtbar, doch in der Nähe des Schillings noch in der Luft 2 witschernd. Am 21. IX. abends gegen 6 Uhr noch mehrere hoch in der Luft am Rennplatze sichtbar. Hier 
waren auch am 23. IX. gegen Abend noch einige zu sehen; es waren die letzten. Doch auch in diesem Jahre fanden sich noch Nachzügler ein, zwar nicht bei Posen, wohl aber in Kolmar i. P., wo am 5. X. einige Rauchschwalben um 1 Uhr mittags über dem Bahnhofe hin und her jagten. Es dürfte sich in diesem Falle um Vögel aus nördlicberen Gegenden gebandelt haben, die einer verspäteten Brut angehörten.

\section{Riparia riparia L.}

Ankunftszeiten, soweit notiert: 2. V. 03; 30. IV. $06 ; 4$. V. 07 (1 St. unter zahlreichen Mehlschwalben bei heftigem Westwinde am Schilling über der Warthe unter Wind hin und her jagend); 29. IV. 08 (1. St.); 30. IV. 09 (mehrere St. unter zahlreichen Rauch- und einigen Mehlschwalben über der Warthe am Schilling).

Die Uferschwalbe bildet in der Nähe von Posen drei mehr oder weniger starke Brutkolonien: a. am rechten sandigen Steilufer der Warthe unterhalb der Militärfähre bei Gluwno, b. in der Sandgrube links des Weges nach Naramowice, wo dieser von der militärfiskalischen Ringstralse gekreuzt wird, und c. oberhalb Posens am rechten Wartheufer gegenüber dem Viktoriapark in der einer Lehmgrube übergelagerten, ein paar Fufs dicken Sandschicht. Am 11. V. 07 waren in a. die ersten Löcher sichtbar, die etwa 1 Fuls unter dem oberen Rande lagen; am 25. V. zahlreiche Erdschwalben in b., die Sandwand ist wie ein Sieb durchlöchert. Es wurden gegen 200 Brutröhren gezählt.

Am 15. V. 08 waren in a. 10 Röhren sichtbar, am 17. war ihre Zahl sichtlich gröfser. Die Vögel wurden leider von nesterplündernden Burschen arg belästigt.

Am 20. V. 09 waren in a. erst wenige Brutlöcher sichtbar (kühle Witterung!); ihre Zahl nahm nur noch um wenige $\mathrm{zu}$, da durch Absturz der sandigen Ufer der Platz ungeeignet geworden war. Am 28. V. wurden in b. gegen 150 Löcher gezäblt. Am 25. VI. zahlreiche Erdschwalben in c., die durcheinander wimmelten wie ein Bienenschwarm.

Wie der Beginn, so wurde auch der Verlauf des Brutgeschäfts durch die Witterung stark beeinflufst, $d$. $h$. in die Länge gezogen. Während am 3.VIII. 08 über einer Lache am Wartheknie bereits eine ansehnliche Schaar Schwalben, dschr oder zirr rufend, der Insektenjagd oblag, wobei man, da die Vögel uns ganz nahe heranliefsen, das leise Knappen der Schnäbelchen deutlich hören konnte, hatten andere nicht nur an diesem Tage, sondern noch am 18. und 19. dieses Monats Junge in ihren Brutlöchen zu füttern, deren Futterschrei man nach dem Einfliegen der Alten deutlich hören konnte; ja einzelne Paare waren noch am 29. VIII., am 1. IX., 3. IX. und 5. IX. (1 Paar in b.) mit der Aufzucht ihrer Jungen beschäftigt. In diesen Fällen dürfte es sich wohl um Ersatzbruten gehandelt haben. Am 7. IX. schwärmte eine Familie, deren Junge offenbar 
erst unlängst ausgeflogen waren, um $6 \mathrm{Uhr} p$ in der Sandgrube vor Naramowice umher, wobei die Jungen tyrr oder zyrr oder zier riefen, während die Alten ihr dschr dschr (oder dschrap) hören lielsen.

Auch im Jahre 1909 zog sich das Brutgeschäft sebr in die Länge, weil durch Absturz der senkrechten Wände in b. zahlreiche Niströhren zerstört worden waren. $\mathrm{Da}$ die abgestürzten Sandmassen zum Teil noch unberührt dalagen, konnten die hier und da freigelegten Nester untersucht werden. Sie bestanden in der Hauptsache aus trockenen Stengelchen und vielen Federn und enthielten Eier. Die Vögel warelı natürlich zu einer Ersatzbrut geschritten. So kam es, dafs im Spätsommer auch die näher am Schilling liegende, sonst von den Schwalben wegen der meist lehmigen Wände gemiedene Grube einige Niströhren aufwies. Auch in der Brutkolonie c. war, wie wir am 18.VIII. sehen konnten, die obere Sandschicht über dem schlüpfrigen Posener Ton etwas abgesunken, doch in einer solchen Stärke, dals die Röhren vielfach unbeschädigt geblieben waren und die Vögel das Brutgeschäft meist glücklich zu Ende bringen konnten.

Die Nacht bringen die Uferschwalben in ihren Niströhren zu. Am 9. VIII. 08 sammelten sich gegen 6 Uhr abends zahlreiche Vögel an der Brutkolonie a. und schwärmten dann, da es wohl zum Einschlüpfen noch zu früh war, eine Zeitlang in der Nähe umber. Dasselbe beobachteten wir in b. Am 5. IX. kamen hier dje ersten um $61 / 4 \mathrm{p}$ an und verschwanden in den Löchern; bis 635 wurden etwa 20 gezählt. Sie kamen in kleinen Vereinen von allen Seiten herbei, besonders von der Warthe ber, tummelten sich noch eine Weile umher und suchten dann gegen Sonnenuntergang oder kurz nachher die Röhren auf. Da ihrer verhältnismälsig nur wenige waren, so ist anzunehmen, dals ein Teil schon abgezogen war. Am 3. IX. 09 versammelten sich um $5^{3} / 4 \mathrm{p}$ zahlreiche Stücke bei a., die teilweise noch umherschwärmten, teilweise auf dem oberen Rande des Steilufers salsen; um 61/4 waren alle in den Röhren verschwunden.

Der Abzug der Uferschwalben vollzog sich Ende August und in der ersten Hälfte des September. 1908 wurden die letzten am 9. IX. gesehen, 1909 am 3. IX.

\section{Delichon urbica L.}

Ankunftszeiten: 1. V. $03 ;$ 5. V. 04; 3. V. 06; 4. V. 07 (Schwarm an der Warthe, unter Wind am Schilling jagend; heftiger Westwind); 30. IV. 08 (1 St. unter einem Trupp Rauchschwalben an der Warthe oberhalb der Badeanstalt von Döring); 27. IV. 09 (anscheinend mehrere St. über der Sandgrube vor Naramowice, sehr hoch fliegend); 30. IV. 09 (mehrere St. unter Raucbschwalben unterhalb des Schillings). 
Beim Nestban wurden Meblschwalben beobachtet am 22. V. 04 am Reduit des Fort Roon (grofse Schleuse). Hier befand sich zu dieser Zeit noch eine ansehnliche Kolonie (30-40 Nester), die aber in den folgenden Jahren immer mehr zusammenschmolz, so dafs am 25. VI. 08 nur noch 3 Nester sichtbar waren, am 19. VI. 09 nur noch ein einziges.

Am 26. V. 07 bauten einige Paare ihre Nester unter dem überhängenden Dache einer Holzscheune vor dem Schlofspark Ostend; auch am 16. VI. 08 wurden ebendort 3 oder 4 Nester gezählt, von denen eins ein Sperling mit Beschlag belegt hatte. Infolge vielfacher Störungen verliefsen die Vögel später diesen Platz. Noch am 4. VIII. 09 wurde 1 St. beobachtet, das Niststoff holte, indem es von dem feuchten Strafsenschmutze vor dem Schillingstore aufnahm; es war in Begleitung eines zweiten Stückes, wohl des Männchens, das sich an der Aufnahme des Materials nicht beteiligte.

Mehlschwalben rotteten sich im Jahre 1909 schon um den Anfang des August zusammen. Am 5. VIII. 09 sahen wir einen starken Schwarm von 150-200 St. auf den Telegraphendrähten in der Nähe des Bahnhofs "Warschauer Tor". Am 21. VIII. tummelten sich zahlreiche Vögel über unserm Schulhofe. Der Abzug zog sich bis in den September, ja stellenweise bis in den Oktober hinein hin: am 3. IX. unterhalb des Schillings gegen Abend zahlreiche Stücke, darunter 2 Mauersegler (vgl. oben p. 420); am 13. IX. noch mehrere Vögel westlich der Schiefsstände vor dem Warschauer Tor hoch in der Luft fliegend und schreiend; am 14. IX. einige zwischen Scbilling und der Strafse nach Naramowice umherfliegend zusammen mit Rauchschwalben; am 12. $X$. wurde (das sei hier beiläufig bemerkt) ein kleiner Trupp in Tütz, Kreis Dt. Krone, Westpreufsen, beobachtet, der dort mehrere Tage verweilte und besonders den Kirchturm umschwärmte, auf dem die Vögel augenscheinlich ihr Nachtquartier hatten (H.).

\section{Bombycilla garrula L.}

Seidenschwänze erscheinen hier offenbar ziemlich selten. Wir haben sie nur zweimal beobachten können und zwar einmal im Herbste und ein zweites Mal im Frühjahr. Am 6. XII. 1903 sals ein Schwarm dieser Vögel im Garten des hiesigen Generalkommandos auf einer Eberesche, deren reichliche Früchte die nordischen Gäste zu mehrtägigem Verweilen veranlafsten. Am 5. IV. 06 trafen wir einen Trupp Seidenschwänze im Bogdankatale unfern der Elsenmühle.

\section{Muscicapa grisola L.}

Ankunftszeiten: 3. V. 03; 7. V. 04; 5. V. 06; 7. V. 07; 8. V. $08 ; 30$. IV. 09 (1 St. an der Nordseite der Kernwerksanlagen, kümmerlich an der Erde Nahrung suchend, auf der es 
sich ziemlich gewandt bewegt; kühles Wetter bei böigen Westwinden).

Der graue Fliegenschnäpper, der hier ziemlich häufig ist, wählte oft seltsame Niststätten. So zog ein Paar in einer schadhaften Gartenlaterne des Eichwaldrestaurants seine Jungen auf: Ein anderes brütete in einer Hängelampe in der Kolonnade der Wolfsmühle. Als hier eines Tages vom Besitzer die Lampe beseitigt wurde, wurde das Nest mit den Eiern herausgenommen und etwa einen Meter von der früheren Stelle entfernt zwischen das Gebälk gesetzt. Der Brutvogel suchte, mehrmals rüttelnd, an der Stelle, wo das Nest gestanden hatte, fand jedoch den neuen Standort nicht und schritt nach einiger Zeit $\mathrm{zu}$ einer Ersatzbrut. In demselben Gartenlokale nistete 1 Pärchen hinter einem an der Kolonnade hängenden Reklameschildchen und brachte die Brut auf. Im Garten des Restaurant Breely brütete 1 Paar mehrere Jahre hintereinander mit Erfolg in einer unter einer Seitenkolonnade hängenden Blumenampel. Es gab den Platz erst auf, als der an der Schmalseite der Kolonnade ausgespannte Leinwandschirm ihm den freien Abflug vom Neste erschwerte. Ein Paar nistete in demselben Garten im Musikpavillon und liefs sich durch die musikalischen Darbietungen durchaus nicht in seinem Brutgeschäfte stören. In den ersten Tagen des August und bis zur Mitte dieses Monats konnten wir vielfach noch Vögel beobachten, die ihre erwachsenen Jungen fütterten, so am 16. VIII. 09 im Vorgarten des Mariengymnasiums, in den Anlagen des Kernwerks, im Schilling. In diesen Fällen haudelte es sich wohl um Spät- oder Ersatzbruten. Die in der Folgezeit beobachteten Vögel hielten zwar eine gewisse Gemeinschaft, doch hatte jedes Glied derselben für sich selbst zu sorgen. Es dürfte sich in diesen Fällen wohl um fremde Durchzügler gehandelt haben, da die einheimischen, sobald die Jungen erstarkt sind, verschwinden. Solche Vögel, meist einzelne oder nur wenige Exemplare, wurden bis zur Mitte des September beobachtet, so am 29. VIII. $082 \mathrm{St}$. auf dem Zaun des Holzplatzes von Krzyzanowski (vor dem ehemaligen Eichwaldtore) und $3 \mathrm{St}$. an der Südwestecke des Eichwaldes; am 3. IX. 081 St. im Schilling; am 4. IX. 1 St. auf den trockenen Ästen der hohen Pappeln an der Wartheseite des Eichwaldes, eifrig Insekten fangend; am 8. IX. vormittags mehrere St. auf dem Petrikirchhofe und nachmittags 2 St. auf den Pappeln an der Wartheseite des Eichwaldes; am 12. IX. um 8/46 p I St. auf der Umzäunung des Holzplatzes yon Krzyzanowski; ebenso am 4. IX. 091 St. auf den dürren Ästen einer Pappel an der Ostseite des Eichwaldes; am 5. IX. morgens um $91 / 4$ Uhr. 1 St. an der Fronleichnamskirche; ebendort am 7. IX. 1 st. morgens um 8 Uhr und um $61 / 2$ p 2 St. auf der dürren Pappel am Holzplatze von Krzyzanowski; am 16. IX. 1 St. im Eichwalde sichtbar und am 17. IX. 1 St. im Schilling auf den trocknen Zweigen einer Weide um $3 / .6 p$ (nach einem heftigen Gewitter, Südwestwind). 


\section{Muscicapa atricapilla L.}

Ankunftszeiten: 11. IV. 02 (1 St. in den Anlagen des Kernwerks); 30. IV. 03; 18. IV. 04 (am Pulverhause hinter dem Kern-

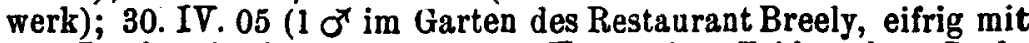
der Insektenjagd beschäftigt); 4. V. 06 (im Fehlanschen Park, heute Goethe-Park); 3. V. 08 (auf dem Petrikirchhofe 1 St., ebendort am 4. $\nabla$. mindestens 8 St. sichtbar, am 5. V. noch 4 St., am 7. V. 1 St.); 29. IV. 09. (1 St. auf dem Kirchhofe hinter dem Schillerdenkmal, während erst der 10. $\nabla$. mehr Vögel brachte, so dafs an der Warthe- und Südseite des Kernwerks 9 St. gezählt werden konnten, meist gepaart; am 12. V. im Eichwalde 6-8 sichtbar; am 13. V. im Kernwerk keiner mehr zu sehen).

Trauertliegenschnäpper berührten auf dem Zuge die Umgebung Posens nicht eben selten, zogen aber nach kurzer Rast weiter, und auffallenderweise blieb nur selten hier und da ein Pärchen zürück, um zur Brut zu schreiten, obwohl beispielsweise unser Eichwald Nistgelegenheiten in Menge bietet. Das geschah zum ersten Male im Jahre 1907, wo am 24. V. ein eifrig singendes ot (die Zugvögel zogen im Frühjahr sang- und klanglos dnrch unser Gebiet) an der Wartheseite des Kernwerks beobachtet wurde. Der Vogel machte sich besonders in der Nähe einer alten Weide am Reitwege zu schaffen. Ein zweites Pärchen hatte sich in einer Weide vor dem Kiefernwäldchen (Nordseite des Kernwerks) links der Strafse nach Naramowice angesiedelt. Beide Vögel wurden an den genannten Plätzen mehrfach beobachtet. Am 2. VI. sangen beide $\sigma^{\top} \sigma^{\top}$ eifrig, während sie sich an den vorhergehenden kühlen Tagen mit Nordostwind still verhalten hatten. In demselben Jahre wurde auch im Eichwalde am 3. VI. (also während der Brutzeit!) ein Pärchen beobachtet; das Ơ sang eifrig. Auch im Jahre 1908 sang am 12. V. ein $\sigma^{7}$ auf den hohen Eichen südlich des Bahndammes und auch am 13. V. und am 16. V. wurde je ein $\sigma^{7}$ an andern Stellen des Eichwaldes gehört, in der Folgezeit aber nicht wieder vernommen; sie scheinen also weiter gezogen zu sein. Während der Trauerfliegenschnäpper bei Posen nur ein seltener Brutvogel war, nistetete er in manchen Gegenden der Provinz ziemlich häufig. Gelegentlich eines Ausfluges nach der Oberförsterei Seehorst wurden 8-10 Pärchen beobachtet, wovon die $0^{\top} \sigma^{T}$ in einer Entferung von 50 bis 100 Schritt von einander in der Nähe eines Grabens eifrig sangen und zum Teil in ihren Brutlöchern aus- und einschlüpften. Ferner wurde dieser Vogel gelegentlich in der Brutzeit beobachtet: in der Forst Górka bei Moschin (17. V. 02), im Buchenwald von Boguniewo (Oberförsterei Eckstelle) und im Jahre 1909 in 2 Paaren im Park von Kobylepole, sowie 1 Paar in der Nähe der Warthefähre bei Owinsk. Auch in der Nähe von Polnisch Mühle bei Schönlanke ist der Vogel regelmäfsiger Brutvogel (S.). 
Auf dem Herbstzuge wurden Trauerfliegenschnäpper viel seltener beobachtet als im Frühjahr. Am 28. VIII. 05 befand sich eine Familie dieser Vögel auf den Wegpappeln an der Nordseite der Kernwerksanlagen; am 31. VIII. I St. in der Wolfsmühle. Am 1. IX. 08 wurde $1 \mathrm{St}$. in einem niedrigen Weidenbusche an der Strafse nach Naramowice $z$ wischen Kirchhof und Sandgrube gesehen. Am 14. IX. 09 trieb sich gegen 5 Uhr p eine Familie im Schilling in der lichten Krone einer hohen Linde umher, eifrig den Insektenfang betreibend, wobei einzelne Stücke ihr bit bit hören liefsen; es waren mindestens 8 Stück. Die Vögel verweilten hier auch noch am 15 ten um 5 Uhr p. Am Morgen des 15. September war der Lockruf von Vögeln dieser Art auch im Vorgarten des Marien-Gymnasiums und am 16. IX. an mehreren Stellen im Eichwalde zu hören.

\section{Muscicapa parva Bchst.}

Am 10. VI. 09 unternahmen wir eine Fahrt nach der Eisenbahnstation Parkowo (Eisenbahn Posen-Schneidemühl), um von hier aus den Buchenwald bei Boguniewo, Oberförsterei Eckstelle, zu besuchen, wo wir den Zwergfliegenschnäpper vermuteten. Unsere Vermutung fand baldige Bestätigung. Kaum waren wir einige 100 Schritt in den Wald eingedrungen, als wir in einer Partie Jungbuchen (Stangenholz) einen Gesang vernahmen, den wir im Posenschen bisher nicht gehört batten. Diese Strophen wichen $\mathrm{zwar}$ in einigen Punkten von dem typischen Gesange des Zwergfliegenschnäppers ab (es fehlte z. B. die Eida-Tour, wie sie ein Vögelchen gelegentlich einer Alpenreise auf dem Alpenrosenwege (bei Füssen) so schön gesungen hatte (H.)), als wir jedoch des kleinen grauen Sängers ansiclitig wurden und sein Benehmen längere Zeit beobachtet hatten, da wurde es uns bald zur Gewifsheit, dals wir den gesuchten glücklich gefunden hatten. Der Vogel begann mit einem grauschnäpperähnlichen tsi tsi oder auch zíe zie; daran fügte er, und damit begann der eigentliche Gesang, 2 hellklingende zití ziti, um dann in eine aus 4 Silben bestehende Tour überzugehen, die wie zi zi zi zi oder manchmal auch wie zink zink zink zink lautete. Darauf folgte in der Regel eine Reihe von 5 allmäblich absinkenden Tönen, in denen regelmäfsig ein Übergang von i zu ü festzustellen war, etwa tji tji tji tjü tjü tjü. Es waren dies angenehme laute Pfeiftöne, die besonders gegen den Schluls hin eine entschiedene Ähnlichkeit mit dem bekannten, etwas sentimental klingenden djü djü djü des Waldlaubrogels aufwiesen. Hörte man das ganze Lied aus einer gewissen Entferung, so erinnerte es uns immer sehr an die liebliche Strophe des Fitis.

Das Vögelchen hielt sich meist in mittlerer Höhe der jungen Buchenstämme auf den unteren Zweigen auf, ohne sich in den Laubkronen $\mathrm{zu}$ verstecken. Trotzdem war es wegen seiner Un- 
stätigkeit recht schwer zu beobachten, so dafs wir nur einmal auf einen flüchtigen Augenblick sein rotes $\nabla$ orhemdchen mit dem Glase beobachten konnten. Der Vogel flog unruhig auf den unbelaubten Teilen der Äste hin und her, fing ein Insekt und sang dann seine Strophe, und hierbei liefs er sich, uns ausweichend, wohl bis $250 \mathrm{~m}$ weit über seinen Standort hinaus treiben, ehe er verstummte.

Als wir darauf in den Buchenhochwald mit seinen prächtigen, alten Stämmen eintraten, merkten wir zu unserer Freude, dafs der vorher beobachtete Vogel nicht der einzige war, dafs vielmehr Zwergfliegenschnäpper sich verhältnismälsig häufig hier angesiedelt hatten. Wir hörten auf unserm Gange durch den Wald, von dem wir nur einen kleinen Teil berührten, noch weitere 4 singende Männchen, die jedoch kein Rot an der Brust zeigten, also jüngere Stücke waren. Auch im Hochwalde trieben sich die Vögel nie in den Kronen, sondern stets auf den unteren Zweigen umher. Ein Stück wurde noch genauer verhört. Sein Lied lautete etwa: tsi (oder manchmal ein leises wíle wile), dann lauter einsetzend: zitf́ ziti ziti zink zink zink zink zink zink tji tjü tjü tjï tjü.

Die Vögel scheinen sich nur im tiefen Walde wohl zu fühlen; an den Waldrändern wurde kein Vogel dieser Art beobachtet.

\section{Lanius excubitor L.}

Raubwürger wurden in unserm Beobachtungsgebiete selten und nur im Frühjahr und im Winter gesehen. Am 21. III. 04 fanden wir, als wir von der Wolfsmühle auf der Fahrstrafse heimwärts gingen, einige 100 Schritt vor der den Fabrweg kreuzenden Ringstrafse auf der abgebrochenen Spitze einer Klette eine noch stark blutende Maus aufgespiefst. Als wir uns der Ringstralse näherten, flog von dem Weidenstrauche an der Kreuzungsstelle der beiden Strafsen ein Raubwürger $a b$ und schlug die Richtung nach der Stelle ein, wo die Beute aufgespiefst war. Am 29. I. 07 safs ein St. an der Westseite des Kernwerks auf der am Eingange zum Kirchhofe stehenden hohen Pappel. Bei unsrer Annäherung flog der Vogel nach dem Felde hin $a b$, rüttelte hier wie ein Raubvogel über einer Stelle des teilweise verschneiten Ackers und kehrte dann auf den Friedhof zurück. Der Schwarm Feldsperlinge, der in einem dichten Busche links am Eingange zum Kirchhofe zu lärmen pflegte, batte sich augenscheinlich aus Furcht vor dem gefährlichen Nachbar verzogen.

Am 13. III. 07 trafen wir wieder an dem Kreuzungspunkte des Fahrweges nach der Wolfsmühle und der Ringstraise auf demselben Weidenbusche wie 1904 einen Raubwürger an, der uns durch sein grüü̈ aufmerksam machte. $O b$ es sich in den angegebenen Fällen um die ein- oder zweispiegelige Form gehandelt hat, wurde leider nicht festgestellt. Der Raubwürger ist selbstverständlich Brutvogel in der Provinz. So hat er mehrere Jahre 
hintereinander in dem Garten des Gutsbesitzers A. Jany in Sarben bei Czarnikau gebrütet, blieb jedoch vom Jahre 1907 an aus.

\section{Lanius minor Gm.}

Der Schwarzstirnwürger ist ein verhältnismälsig seltener Brutvogel unsres Gebietes. Das öftere und längere Verweilen des Vogels an der Wolfsmühle legte die Vermutung nahe, dafs er hier brüte. So trieb sich am 23. V. $061 \mathrm{St}$. auf der nahen Wartheinsel umber; jedoch gelang es uns zunächst nicht, etwas Sicheres zu erkunden. Unsre Vermutung verdichtete sich jedoch zur Wahrscheinlichleit, als wir am 28. VI. des folgenden Jahres (1907) mehrere Vögel dieser Art in der Nähe der Wolfsmühle beobachten konnten, die hier erbrütet zu sein schienen. Am 27. V. 08 gelang es uns endlich, den Vogel am Nest zu beobachten, Er nistete auf der ersten Spitzpappel, seinem Lieblingsbaume. links am Eingange zur Wolfsmühle. Das Nest stand in einer Gabel eines der untersten Zweige in einer Höhe von ungefähr $6 \mathrm{~m}$ etwa 2 Fufs vom Stamme entfernt. Es waren bereits Junge im Nest, deren Futterruf unsre Aufmerksamkeit erregt hatte. Ein alter Vogel trug gerade Futter herbei. Am 14. VI. waren die Jungen bereits ausgeflogen und wurden in der Nähe des Nistbaumes auf einer dichtbelaubten Kopfweide gefüttert. Auch im Jahre 1909 wurde am 20. V. der Vogel in der Nähe der Wolfsmühle auf einer Spitzpappel gesehen, auf der er mehrmals jarrik rief. Er trieb sich auch in der Folgezeit hier umher und hat auch zweifellos hier wieder gebrütet. Ein Gesang wurde von diesen Vögeln nicht vernommen, wohl deshalb nicht, weil sie schon durch das Brutgeschäft zur sehr in Anspruch genommen waren.

Dagegen trafen wir am 5. V. 07 auf einer der Wegpappeln zwischen Bogdanka und Eisenbahndamm (diesseits der Elsenmühle) in der Nähe des Bahnüberganges einen einzelnen Vogel dieser Art, der eifrig sang und in seinen Gesang Strophen des Lerchengesanges, die Flötentöne des Pirols und Rufe des Stars einflocht. Der Vogel wechselte von hier nach einem Birnbaum hinüber, dann auf die Telegraphendrähte am Bahnkörper, von denen er wiederholt nach Würgerart zur Erde flog, um Beute aufzunehmen.

Am 17. V. desselben Jahres sahen wir ein Pärchen dieser Vögel westlich der Loncz-Mühle an der Ringstrafse gegenüber dem Spechtschen Schielsstande. Der eifrige Gesang des $\sigma^{\top}$ liefs Anklänge an den Gesang der Lerche, des Gartenammers, des Buchfinken, des Pirols und auch des Sperlings erkennen. Die Gesangsleistung des Grauwürgers blieb jedoch zweifellos hinter der seines Vetters, des Rotrückenwürgers, erheblich zurück.

\section{Lanius collumio L.}

Der rotrückige Würger ist in der Umgebung Posens recht häufig. Er trifft hier regelmäfsig in der ersten Hälfte des Mai ein. 
Ankunftszeiten: 11. V. 01 (eifrig singend an der Südseite der milit. Schielsstände vor dem Warschauer Tor); 6. V. 03; 7. V. $04 ; 3$. V. $05 ; 13$. V. $06 ; 8$. V. $07 ; 11$. V. $08 ; 12$. V. 09.

Der Dorndreher, der ja als arger Nestplünderer gilt, scheint sich hier schlecht und recht durch die Welt zu schlagen, jedenfalls haben wir nur aufgespielste Hummeln und andere Insekten gefunden und auch das nur selten, so dafs man meinen könnte, der Vogel habe hier diese Gewohnheit so ziemlich aufgegeben. Nur einige wenige Male trafen wir den Vogel in verdächtigen Situationen an. So sahen wir einst ein altes ơ in den Kernwerksanlagen in der Nähe eines Buchfinkennestes, in dem nackte Junge lagen. Der Vogel batte, wie es uns schien, seine begehrlichen Blicke darauf gerichtet. Am nächsten Tage war in der Tat das Nest ausgeplündert. Ein andermal trieb sich $1 \mathrm{St}$. im Schilling in der Nähe eines zerstörten Buchfinkennestes, in dem Reste von Eiern lagen, umber, und ein Buchfinkenmännchen machte wiederholt heftige Angriffe auf den Würger, was diesen freilig wenig störte. Häufig trafen wir Grasmücken, Dorn- wie Sperbergrasmücken, ganz in seiner Nähe an, und solange keine Jungen da warell, schien das Verhältnis ein leidliches $z u$ sein, d. h. das gegenseitiger Duldung. Waren jedoch die Jungen ausgeschlüpft, so gebärdeten sich dio Grasmücken sebr ängstlich, wenn ihnen der Rotrückige zu nahe kam.

Gesangsleistungen wurden trotz der ansehnlichen Zahl der Vögel nur von wenigen Männchen beobachtet. Ein St. kopierte einst vor dem ehemaligen Eichwaldtore den Buchfinkenschlag mit vollendeter Meisterschaft, nur war der Ton dünner. Ein Künstler dieser Art wurde am 15. VI. 07 an der Wartheseite des Rennplatzes beobachtet. Der Vogel gab zuerst ein Lied im Tone des Sumpfrohrsängers zum besten, so dafs wir uns in der Tat zunächst täuschen liefsen. Dann imitierte er ganz famos den Rebhahn und liefs ein paar klirrende Strophen des Braunkehlchens bören. Beide Vögel waren öfter in seiner Nachbarschaft zu hören. Der Angriff eines Budytes-Männchens liefs ihn völlig kalt. Er safs auf einem trockenen Zacken eines Strauches und flog, als wir ihm zu nahe kamen, nach der andern Seite der Warthe hinüber. Ein anderes $\sigma^{\top}$ ahmte am 12. V. 09 am Wartheufer östlich des Viktoriaparks deutlich Baumpieper, Rebhahn und Blaukehlchen nach. Auch hier waren diese Vögel in der Tat ansässig.

Besonders zahlreich hatten sich Dorndreher in den Anpflanzungen (viele Fichten) an der Ringstrafse zwischen Dembsen und dem Eichwalde angesiedelt. Hier wurden am 4. VI. 08 auf etwa $1 \mathrm{~km} 5 \sigma^{\Upsilon} \sigma^{\Upsilon}$ gezählt, immer in einer gewissen Entfernung von einander, also augenscheinlich Brutvögel. Die Jungen waren anfangs August meist schon selbständig, doch waren auch noch manche in der Obhut der Alten, ja wir trafen sogar noch solche, die erst halbflügge waren. Auf ein solches wurden wir am 5. VIII. 08 durch das ängstliche täk des mit dem Schwanze hin 
und her rudernden $\sigma^{\top}$ aufmerksam gemacht. Als wir das Junge in seinem Busche greifen wollten, warf es sich ohne weiteres zu Boden und war im Pflanzengewirr trotz eifrigen Suchens nicht zu finden. Das Nest, das noch nicht lange verlassen sein konnte, stand in der Näbe im Hopfengerank. Von den Geschwistern war nichts zu bemerken; es war also wohl das Nesthäkchen. Als wir uns eine Weile still verhielten, kamen die Alten herbei, und das Junge liefs das bekannte Futtergeschrei hören. Es hatte also trotz seiner Hülflosigkeit sich der drohenden Gefahr wohl zu entziehen verstanden.

Der Abzug dieser Vögel erfolgte Ende August oder im September, und zwar schienen bei dieser Art meistens die Alten vor den Jungen fortzuziehen; jedenfalls waren die in der zweiten Hälfte des August und später beobachteten Vögel meistens Junge. Sie salsen gern auf Zäunen (z. B. auf der Umzäunung des Kartmanuschen Holzplatzes an der Eichwaldstrafse, auf dem Drahtzaun des Rennplatzes) und lagen der Insektenjagd ob. Im Jahre 1905 saben wir den letzten am 2. X. an der Wartheseite des Rennplatzes, im Jahre 1909 am 21. IX. ebendort 2 St.

\section{Lanius senator L.}

Der Rotkopfwürger wurde hier im ganzen viermal auf dem Durchzuge im Frübjahr beobachtet: am 30. IV. $021 \mathrm{St}$. in dem Birkenwäldchen vor Solatsch; ebendort anscheinend ein Paar am 19. V. 04; ein einzelnes St. in den milit. Schielsständen vor dem Warschauer Tor; ein Paar in der Nähe des Viktoriaparks. Hier wurde am 22. V. 09 um $3 / 6$ p zunächst 1 St. auf den Weiden und Erlen westlich des genannten Parks gesehen, das nach Würgerart von einem Baume zur Erde flog, Beute aufnahm und wieder an seinen Standort zurückkehrte. Bald wurde in einiger Entfernung ein $\mathrm{zweites} \mathrm{St.} \mathrm{gesichtet,} \mathrm{das} \mathrm{mattere} \mathrm{Farben} \mathrm{aufwies,}$ also das Weibchen. Schliefslich safsen beide Gatten unfern von einander auf einer Weide an der Wiese. In der Folgezeit wurden die Vögel hier nicht wieder gesehen.

\section{Corvus cornix L.}

Mit welcher Hartnäckigkeit unser Graumantel eine einmal ins Auge gefafste Beute verfolgt, zeigt folgender Vorfall. Als wir eines Nachmittags von der Wolfsmühle aus den Heimweg antrateu, sahen wir von weitem einen Hasen, der nur mit Mühe die wiederholten, heftigen Angriffe eines Krähenpaares durch Pfotenhiebe abwies. Unsre Vermutung, dafs der Hase ein Junges vor den Räubern zu schützen suche, bestätigte sich, als wir uns dem Schauplatze dieser eigentümlichen Kämpfe näherten. Die Angriffe der Krähen galten einem etwa faustyrofsen Häschen, das die Mutter mit anerkennenswerter Beherztheit verteidigte. Die Häsin nahm schliefslich vor uns Reifsaus, und der zappelnde, 
uns schon kräftig anfauchende Junghase geriet in unsere Hände. Die beiden Wegelagerer zogen nun nicht etwa von dannen, sondern warteten, wenn auch in angemessener Entfernung, das Weitere ab. Unser wiederboltes Scheuchen half gar nichts; erst einige Steinwürfe bewogen sie zum Abzuge. Den Junghasen setzten wir in ein nahes Roggenfeld, um ihn den Späheraugen der etwa zurückkehrenden Räuber zu entziehen.

Am 16. V. 04 beobachteten wir eine Krähe, die in dem Kiefernwäldchen an der Nordseite des Kernwerks links des Weges nach Naramowice durch ungestüme Angriffe ein Eichhörnchen aus seinem Brutreviere vertrieb, das denn auch murrend und fauchend den Stölsen des Verfolgers auswich und das Feld räumte. Im Winter des Jahres 1908 und 1909 konnten wir häufig Krähen in der Warthe in der Nähe des Schillings fischen sehen. Die Vögel liefsen sich mit nach unten ausgestreckten Beinen vorsichtig bis zur Oberfläche des Wassers herab und nabmen Frefsbares mit dem Schnabel auf, um es dann, wenn es ein gröfserer Bissen war, am Ufer sitzend zu verzehren (22. II. 08 und sonst häufig). Hier und da liels sich auch wohl eine auf einer winzigen Eisscholle treiben, um von hier aus Zusagendes mit dem Schnabel $\mathrm{zu}$ erhaschen (13. II. 09).

Am 28. V. 08 waren in einem Neste, das im Wipfel einer Kiefer in dem vorher genannten Wäldchen stand, erwachsene Junge, von denen eins auf dem Nestrande und den nahen Zweigen herumturnte. Auf den leisen Warnruf eines Alten hin drückte es sich sogleich im Neste nieder und verhielt sich regungslos.

Nach Beendigung des Brutgeschäfts teiben sich die einzelnen Familien eine Zeitlang auf den Feldern umher, scheinen dann aber allmählich fortzuziehen, wenigstens sind im Spätsommer hier auffallend wenig Kräben vorhanden. Erst der Herbst bringt Zuzug. Diese zugewanderten Vögel fliegen regelmärsig des Abends einem gemeinsamen Schlafplatze zu. Ein bevorzugter Schlafplatz, den die Graukrähen meist erst ziemlich spät und lautlos aufzusuchen pflegten, war das Kiefernwäldchen unterbalb der Militärfähre unfern des Schillings.

\section{Corvus frugilegus L.}

In den 90er Jabren befand sich eine Saatkrähenkolonie auf den hohen Kiefern am Nordrande des Eichwaldes, die jedoch durch stete Beunruhigung ausgerottet wurde. Am 4. IV. 06 konnten wir auf dem Petrikirchhofe eine im Entstehen begriffene Ansiedlung von Saathrähen beobachten. Am 5. IV, zählten wir auf mehreren hohen Robinien 12 Nester, die gröfstenteils vollendet waren. Am 19. IV. waren die Nester verschwunden; sie waren von der Feuerwehr heruntergeholt worden.

Am 14. III. 07 sahen wir eine einzelne Saatkrähe in einem Starenschwarm, die augenscheinlich mit den Staren um dieWette flog. 
Am 25. III. 07 begannen die Saatraben in Lubasch ( $\mathrm{Kr}$. Czarnikau) zu nisten, indem die vorhandenen Nester ausgebessert und neue angelegt wurden. Die dortige starke Kolonie befindet sich im herrschaftlichen Parke. Die Vögel, deren unausgesetztes Lärmen geradezu unleidlich wird, lassen sich durch die hartnäckigsten Verfolgungen nicht vertreiben. Die Nester stehen fast nur auf den auf sumpfigem Untergrunde wachsenden Erlen.

Während man in der Umgebung Posens im späten Frühjahr und im Sommer nur wenige oder auch keine Saatraben zu sehen bekommt, wird etwa von der Mitte des September an ihre Zahl durch Zuwanderung immer gröfser. Im Jahre 1907 und auch in der Folgezeit war der Hauptschlafplatz der hier überwinetrnden Saatkrähen das kleine Kiefernwäldchen unterhalb der Militärfähre westlich von Gluwno. Viele Hunderte von V.ögeln übernachteten hier und liefsen sich auch durch die vielfachen Störungen, die das grolse Festungsmanöver mit sich brachte, das sich besonders in jener Gegend abspielte, nicht vertreiben. Gegen Abend kamen die Vögel aus allen Himmelsrichtungen geflogen, sammelten sich auf den nahen Äckern zu grofsen Scharen an, um dann bei eintretender Dunkelheit den gewohnten Schlafplatz zu beziehen.

Überhin ziehende Trupps dieser Vögel zeigten sich manchmal recht scheu. So flogen am 14. IX. 09 gegen $51 / 4$ p 20 Stück, lebhaft schreiend, etwa $200 \mathrm{~m}$ hoch über die Sandgrube vor Naramowice hinweg gen Westen (Westwind).' Als wir unser Glas auf sie richteten, wichen sie sofort seitwärts aus und nahmen erst nach einer Weile wieder die alte Richtung auf. Sie schienen bereits üble Erfahrungen gemacht zu haben.

Am 20. IX. 09 zog ein Schwarm von mindestens 50 St. schreiend von Westen her über die Warthe, kreiste eine Weile über dem Kiefernwäldchen unterhalb der Fähre, bog dann aber nach Nordwest ab und schlug die Richtung nach Umultowo ein. Unfern dieses Dorfes nisten alljährlich nnch zuverlässigen Mitteilungen zahlreiche Vögel dieser Art. Auch am 13. X. hielten zablreiche Saatraben dieselbe Richtung 5 Uhr $p$, mit Dohlen vereint, und ebenso am 18. X. starke Schwärme. Erst allmählich gewöhnten sich die Vögel wieder daran, in dem vorher genannten Kiefernwäldchen zu nächtigen. Am 24. X. näherte sich um $3 / 45$ p von Südosten her ein sehr starker Schwarm dem Wäldchen. Die Vögel schwärmten noch einige Zeit unschlüssig hin und her und fielen erst, als es schon ziemlich dunkel war, ein. Von nun an übernachteten hier wieder den ganzen Winter hindurch gewaltige Scharen dieser Vögel im Verein mit Dohlen. Erst im letzten Drittel des Februar nahm ihre Zahl merklich ab, während die Dohlen den Platz noch bis tief in den März hinein behaupteten, ja selbst im Anfange des April noch Abends in kleinen Flügen dem genanoten Schlafplatze zustrebten.

(Schlurs folgt.) 